\title{
Optimization of magnetic force microscopy for retrieval of data from an erased or altered audiotape
}

\author{
Chandar Prasad Palamadai Subramanian \\ West Virginia University
}

Follow this and additional works at: https://researchrepository.wvu.edu/etd

\section{Recommended Citation}

Palamadai Subramanian, Chandar Prasad, "Optimization of magnetic force microscopy for retrieval of data from an erased or altered audiotape" (2008). Graduate Theses, Dissertations, and Problem Reports. 1984.

https://researchrepository.wvu.edu/etd/1984

This Thesis is protected by copyright and/or related rights. It has been brought to you by the The Research Repository @WVU with permission from the rights-holder(s). You are free to use this Thesis in any way that is permitted by the copyright and related rights legislation that applies to your use. For other uses you must obtain permission from the rights-holder(s) directly, unless additional rights are indicated by a Creative Commons license in the record and/ or on the work itself. This Thesis has been accepted for inclusion in WVU Graduate Theses, Dissertations, and Problem Reports collection by an authorized administrator of The Research Repository @ WVU. For more information, please contact researchrepository@mail.wvu.edu. 


\title{
Optimization of Magnetic Force Microscopy for Retrieval of Data from an Erased or Altered Audiotape
}

\author{
by \\ Chandar Prasad Palamadai Subramanian \\ Thesis Submitted to the \\ College of Engineering and Mineral Resources \\ at West Virginia University \\ in partial fulfillment of the requirements \\ for the degree of \\ Master of Science \\ in \\ Chemical Engineering \\ Charter D. Stinespring, Ph.D., Chair \\ Alfred H. Stiller, Ph.D. \\ John W. Zondlo, Ph.D. \\ Department of Chemical Engineering \\ Morgantown, West Virginia \\ 2008
}

Keywords: Magnetic Force Microscopy, Audiotape, Waveform, Data

Recovery

Copyright 2008 Chandar Prasad Palamadai Subramanian 


\begin{abstract}
Optimization of Magnetic Force Microscopy for Retrieval of Data from an Erased or Altered Audiotape

by

Chandar Prasad Palamadai Subramanian

Master of Science in Chemical Engineering

West Virginia University

Charter D. Stinespring, Ph.D., Chair

Magnetic force microscopy (MFM) has been used to investigate the potential for retrieving information from an erased or altered audiotape. The audiotape recording process, the reasons for the distortion of signals during the recording process are presented. An in-depth study has been conducted to investigate the effects of MFM operation parameters on the data retrieval process. Most importantly, these include interleave height and tip speed. Interleave height (i.e., the height of the MFM tip above the surface) has been optimized for maximum clarity of MFM images. Tip speed studies have been carried out to optimize the data retrieval time and suggestions to further reduce the retrieval time are also made. A study has also been performed using MFM to determine the maximum frequency that could be recorded on an audiotape. This optimization of MFM suggests a novel technique for the retrieval of data from erased or altered audiotape.
\end{abstract}




\section{DEDICATION}

To her, whose very thought creates a strong vigour in my mind and instills a hope of that which is auspicious. To her, who had taught me all the good qualities that I possess. To her, who showered unconditional love and rendered support during the most demanding times of my life. To the natural bond between us which serves as a constant source of inspiration and guidance, even today. Words fail to express the memories with her that produce unspeakable happiness in my heart. To my late mother, I dedicate this thesis. 


\section{ACKNOWLEDGEMENTS}

First of all I would like to express my deepest gratitude to my advisor Dr.Charter D. Stinespring, without whose continuous guidance, encouragement and support, none of this research would have been possible. My sincere thanks, also, to the chemical engineering department of West Virginia University (WVU) for providing me such a wonderful opportunity to pursue masters by research program.

My thesis would be incomplete without my immediate mentor, Dr.Andrew Woodworth, who taught me the experimental setup, struggled with me in aligning the laser and focusing the camera, took care of me like a little brother, showed tremendous patience and guided me in all possible ways.

I would also like to express my reverence towards my father, P S Subramanian, for his affection, encouragement and support throughout my life. My earnest thanks and appreciation to my brother, P S Shyaam Prasad, for boosting my confidence and passing valuable remarks. I also want to thank my grandmother and aunt for their love and enthusiasm.

Appreciation is also due to my other lab mates Srikanth Raghavan and Tobias Denig for their witty and inspiring comments during the experimental sessions. I cannot thank enough, my fellow students, particularly Adam Finniss, Ashish Bambal, Christopher Yurchick, Jason Hissam and Steve Markovich for the endless conversations in the graduate lounge which made me feel at home. I wish you all the very best for a fantastic research and a wonderful life.

My thanks to Dr. Alfred H. Stiller and Dr. John W. Zondlo for agreeing to be a part of my thesis defense committee. Bonita Helmick and Linda Rogers also deserve my thanks for helping me to fulfill the requirements of successful graduation, providing wonderful and economical coffee within the department.

My special thanks to my friends Arvind Ramanan, Bhaskar Raman, Karthik Ravirajan, Rajsundar Elangovan, Shrutisagar Chandrasekaran, Sivaram Ramasubramanian and Vijay Narayanan for calling and stimulating me regularly, especially during my writing sessions which was mostly late in the night and occasionally during the wee hours of the morning. 
My genuine thanks to the funding agency ${ }^{*}$ of this research project, without which, the project would not have progressed and would have also caused a severe financial burden on me.

Last but not least, nothing is possible without the grace of God. I feel this is the right occasion to show my sincere surrender to the "supreme" for giving me wisdom, opportunity and all good things.

*This project was funded by The US Government.

(Federal Government Contract Number: 2004*P97500*000) 


\section{TABLE OF CONTENTS}

$\begin{array}{ll}\text { ABSTRACT } & \text { ii }\end{array}$

DEDICATION

ACKNOWLEDGEMENT

TABLE OF CONTENTS Vi

LIST OF FIGURES viii

LIST OF TABLES X X

Chapter 1: Introduction 1

1.1 Motivation 1

1.2 Problem Statement 1

1.3 Thesis Outline 4

Chapter 2: Audiotape and Recording Process 5

2.1 Audiotape 5

2.2 Erase, Record \& Reproduce Process $\quad 8$

2.3 Data Format

Chapter 3: Literature Review 11

3.1 Imaging of Overwritten Data using MFSTM 11

3.2 Recovery of analog signals using MRM 14

Chapter 4: Experimental Approach 16

4.1 Classification of Scanning Probe Microscopy 16

$\begin{array}{lr}\text { 4.2 Magnetic Force Microscopy } & 18\end{array}$

$\begin{array}{ll}\text { 4.2.1 Principle } & 18\end{array}$

$\begin{array}{ll}\text { 4.2.2 System Operation } & 19\end{array}$ 
4.2.3 Magnetic Force Microscope Setup 21

4.2.4 Mathematical Representation $\quad 23$

4.2.5 Scanning Probes or Tips 26

$\begin{array}{ll}4.3 \text { Recording Process } & 27\end{array}$

Chapter 5: Results and Discussion $\quad 32$

5.1 Data Distortion During Recording and Playback 32

5.2 Interleave Height Study 37

5.3 Tip Speed Study 42

5.4 Frequency Study $\quad 45$

5.5 Calculation of Time for Recovery of Data 52

Chapter 6: Conclusions $\quad 54$

Appendix A: Procedure for Operating the MFM 56

Appendix B: Procedure for Operating MFM Images 60

Appendix C: Procedure for Converting MFM Images to Grey Scale 61

$\begin{array}{ll}\text { Bibliography } & 62\end{array}$ 


\section{LIST OF FIGURES}

Figure 1.1 Schematic illustrating the effects of hysteresis on magnetization 2

$\begin{array}{lll}\text { Figure 2.1 Schematic of Audiotape } & 6\end{array}$

Figure 2.2 Domain of each Magnetic Particle 6

Figure 2.3 Schematic representation of the head of the audiotape 9

Figure 2.4 Data Format of the audiotape 10

$\begin{array}{lll}\text { Figure 3.1 MFSTM image of a commercial disk } & 13\end{array}$

$\begin{array}{lll}\text { Figure } 3.2 & \text { MFSTM image of overlapping region } & 13\end{array}$

$\begin{array}{lll}\text { Figure 3.3 MRM image of the word FBI } & 14\end{array}$

Figure 3.4 Expanded view of the image shown in Figure 3.3 in the region of the

letter "I" 15

$\begin{array}{lll}\text { Figure 4.1 Schematic of classification of SPM } & 17\end{array}$

$\begin{array}{lll}\text { Figure } 4.2 & \text { Inter-atomic Force vs. Distance curve } & 18\end{array}$

$\begin{array}{lll}\text { Figure 4.3 Setup of MFM cantilever and sample } & 21\end{array}$

Figure 4.4 Schematic of Magnetic Force Microscopy 22

Figure 4.5 Photograph of MFM instrument 25

Figure 4.6 Image of SPM probe with frequency of $75 \mathrm{kHz}$

$\begin{array}{lll}\text { Figure } 4.7 & \text { Drawing illustrating recording process setup } & 28\end{array}$

$\begin{array}{lll}\text { Figure } 4.8 & \text { Photo of the audiotape } & 29\end{array}$

$\begin{array}{lll}\text { Figure 4.9 Graph of input/output signal } & 29\end{array}$

$\begin{array}{lll}\text { Figure 4.10 Picture of encased recorded audiotape } & 30\end{array}$

$\begin{array}{lll}\text { Figure 4.11 Audiotape stuck onto the scan stand } & 31\end{array}$

Figure 4.12 Sketch illustrating a number of regions on the audiotape 31 
Figure 5.1 Recorded waveform of square wave 34

Figure 5.2 Recorded waveform of saw-tooth wave 35

Figure 5.3 Recorded waveform of sine wave 36

Figure 5.4 MFM image of $2 \mathrm{kHz}$ Sine wave with interleave of $100 \mathrm{~nm}$

Figure 5.5 MFM image of $2 \mathrm{kHz}$ Sine wave with interleave of $200 \mathrm{~nm}$

Figure 5.6 MFM image of $2 \mathrm{kHz}$ Sine wave with interleave of $300 \mathrm{~nm}$

Figure 5.7 Schematic of different regions of interest 43

Figure 5.8 Plot of Correlation vs. Tip Speed 44

Figure 5.9 MFM image of $10 \mathrm{kHz}$ sine wave 46

Figure 5.10 MFM image of $15 \mathrm{kHz}$ sine wave $\quad 47$

Figure 5.11 MFM image of $20 \mathrm{kHz}$ sine wave 48

Figure 5.12 MFM image of $22.5 \mathrm{kHz}$ sine wave 49

Figure 5.13 MFM image of $23 \mathrm{kHz}$ sine wave $\quad 50$

Figure 5.14 MFM image of $24 \mathrm{kHz}$ sine wave 51

Figure 5.15 Schematic of Millipede 53

Figure A.1 Photograph of scanner on mounting jig 57

Figure A.2 Schematic of areas of MFM scans 58 


\section{LIST OF TABLES}

Table 1.1: Magnetic coating materials based on application 


\section{Chapter 1 Introduction}

\subsection{Motivation}

Magnetic media is commonly used to store data. Various examples of magnetic storage devices are computer hard disks, video tapes, data tapes and audio tapes. Of particular interest are audiotapes because of their wide availability and usage. In fact around 500,000 audio cassettes are being used by UK police force for interviews [1]. The data stored in audiotape can be lost due to alterations or damage, and therefore techniques to recover lost data are of interest. To date several forensic methods are available to determine if the media has been altered. However none of these studies has recovered erased or overwritten data. A major problem in the previous studies has been the use of techniques which average over relatively large areas of the audiotape as compared to the individual magnetic domains which store the information. Research performed in this laboratory has addressed the question of whether a high resolution technique, such as magnetic force microscopy (MFM), may provide the information needed to reconstruct data from media which has been erased or overwritten.

\subsection{Problem Statement}

When a ferromagnetic material is magnetized, it does not loose it magnetization even when the magnetizing field is removed. This property of not being able to return to is called hysteresis. Also, if the applied field is an alternating field, then the material will trace out a magnetization loop called the hysteresis loop as shown in Figure 1.1. This property of hysteresis is due to the presence of magnetic domains in the material. When the applied field orients these domains in a particular way, it requires some amount of 
energy to bring them back to the original state. This is the reason for the magnetic memory in these materials.

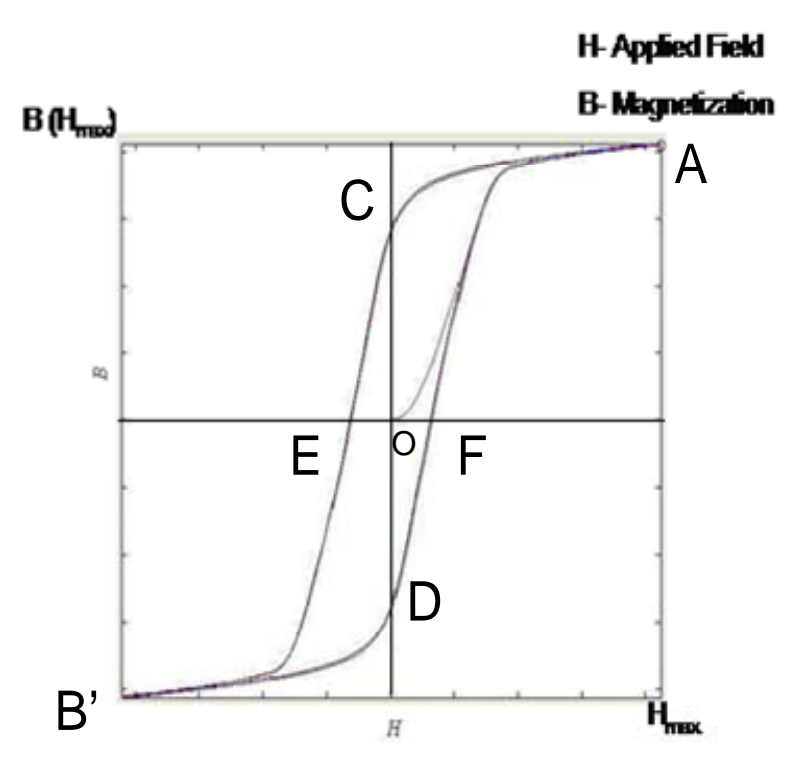

Figure 0.1 Schematic illustrating the effects of hysteresis on the magnetization.

In Figure 1.1, the applied field is denoted by $\mathrm{H}$ is plotted along the $\mathrm{x}$-axis and the resultant magnetization $\mathrm{B}$ is plotted along the $\mathrm{y}$-axis. As the applied field increases, the resultant magnetization from the origin also increases resulting in the maximum observed magnetization $\mathrm{B}\left(\mathrm{H}_{\max }\right)$ for a value of $\mathrm{H}_{\max }$. This is denoted by the curve OA. At this point an increase in the applied field will produce negligible or no increase in the resultant magnetization. When $\mathrm{H}$ is reduced to zero, the curve moves from point $\mathrm{A}$ to point $\mathrm{C}$, indicating residual or remnant magnetization. Some ferromagnetic materials retain the imposed field for a long period of time which makes them called permanent 
magnets. When the magnetizing force is reversed, the curve traverses to point E where the flux is zero. As the magnetizing force is further increased in the opposite direction, it will result in saturation magnetization in the opposite direction, denoted by the point B'. Again reducing the applied field to zero will bring the curve to point F. Increasing the applied field will return the curve to zero. It is to be noted that additional energy is needed to bring the material back to its unmagnetized state at the origin. This hysteresis is the basis for the recording process and it also provides the potential that remnant information may be found after erasure or alteration.

This thesis investigates the idea of recovering the altered or erased data from an audiotape using MFM. To our knowledge, MFM technique has not been used to recover erased data. Current data recovery methods such as ferro-magnetic imaging or magneto resistive imaging average many particles at once. These techniques have been used for forensics investigations of data alteration but not data recovery.

Pappas et al. [2] in their work showed the possibility of recovering data from damaged audiotapes but even in this case, erased data were not recovered. Also the investigations of Gomez et al. [3] over magnetic disks have not used MFM to recover erased data. Therefore, investigations using a high resolution technique such as MFM are necessary to construct a conclusive statement.

The primary goal of this research project is to retrieve erased or overwritten information on an audiotape using MFM. This goal has been met and the research has been described in the thesis of my colleague Mr.Terry R. Ferrett [4]. The goal of the research described in this thesis is to optimize the MFM data acquisition process for retrieval of erased or overwritten audiotape data. 


\subsection{Thesis Outline}

The purpose of this section is to provide a roadmap for the reminder of the thesis. Chapter 2 deals with the audiotape and the recording process. Section 2.1 covers audiotape structure and chemistry. Section 2.2 deals with the audiotape recording process. The audiotape data format is explained in Section 2.3.

Chapter 3 reviews the primary literature used for this research. Section 3.1 reviews the work of Gomez et al. [3] which showed complete erasure of overwritten data is impossible. The second harmonic magneto resistive imaging technique used by Pappas et al. [2] to recover data from magnetic storage media is discussed in Section 3.2.

Chapter 4 describes the experimental methods used in this research. Section 4.1 introduces the concept of scanning probe microscopy and its major divisions. Scanning probes or tips are described in Section 4.2. Section 4.3 describes the recording process of waveforms (samples) for this research. The basic principle, system operation, setup and mathematical basis for MFM technique are discussed in Section 4.4.

The results are covered in Chapter 5. The results cover a wide range of concepts from the distortion of the wave during the recording process to the time required to retrieve the signal from the audiotape.

Chapter 6 starts with the conclusions based on the research work done and ends with suggestions for future work. 


\section{Chapter 2 Audiotape and the Recording Process}

\subsection{Audiotape}

An audiotape is a polymer tape coated with magnetic material. The polymer is usually polyethylene terephthalate (PET) and the magnetic coating is done with various materials such as chromium oxide $\left(\mathrm{CrO}_{2}\right)$ or iron oxide $\left(\mathrm{Fe}_{2} \mathrm{O}_{3}\right)$ film. A detailed list of magnetic coating materials and their application can be found in Table 2.1 [5].

The most commonly used coating material for audiotape is $\gamma-\mathrm{Fe}_{2} \mathrm{O}_{3}$ film coated with cobalt. Studies have shown that the thermal stability of the tape is enhanced by the cobalt coating [6]. Also tape demagnetization is not as serious an issue with the cobalt coating as it is with the $\gamma-\mathrm{Fe}_{2} \mathrm{O}_{3}$ doped with cobalt [6].

Figure 2.1 shows the schematic of the audiotape showing the nominal dimensions of the coating and the PET substrate. The thickness of the polymer substrate is around 5 to $10 \mu \mathrm{m}$ and that of the magnetic coating is approximately $5 \mu \mathrm{m}$. Typically the particle density varies from $300-600$ particles $/ \mu \mathrm{m}^{3}$. A single magnetic domain particle is as illustrated in Fig 2.2. The magnetic domain is a region where the magnetic field vectors of individual atoms are arrayed in the same direction. It can be viewed as a magnet itself in a smaller scale. The lines emanating from the domain represent the magnetic field exhibited by them. The convention is that the direction of the field vector is from the north pole to south pole. 

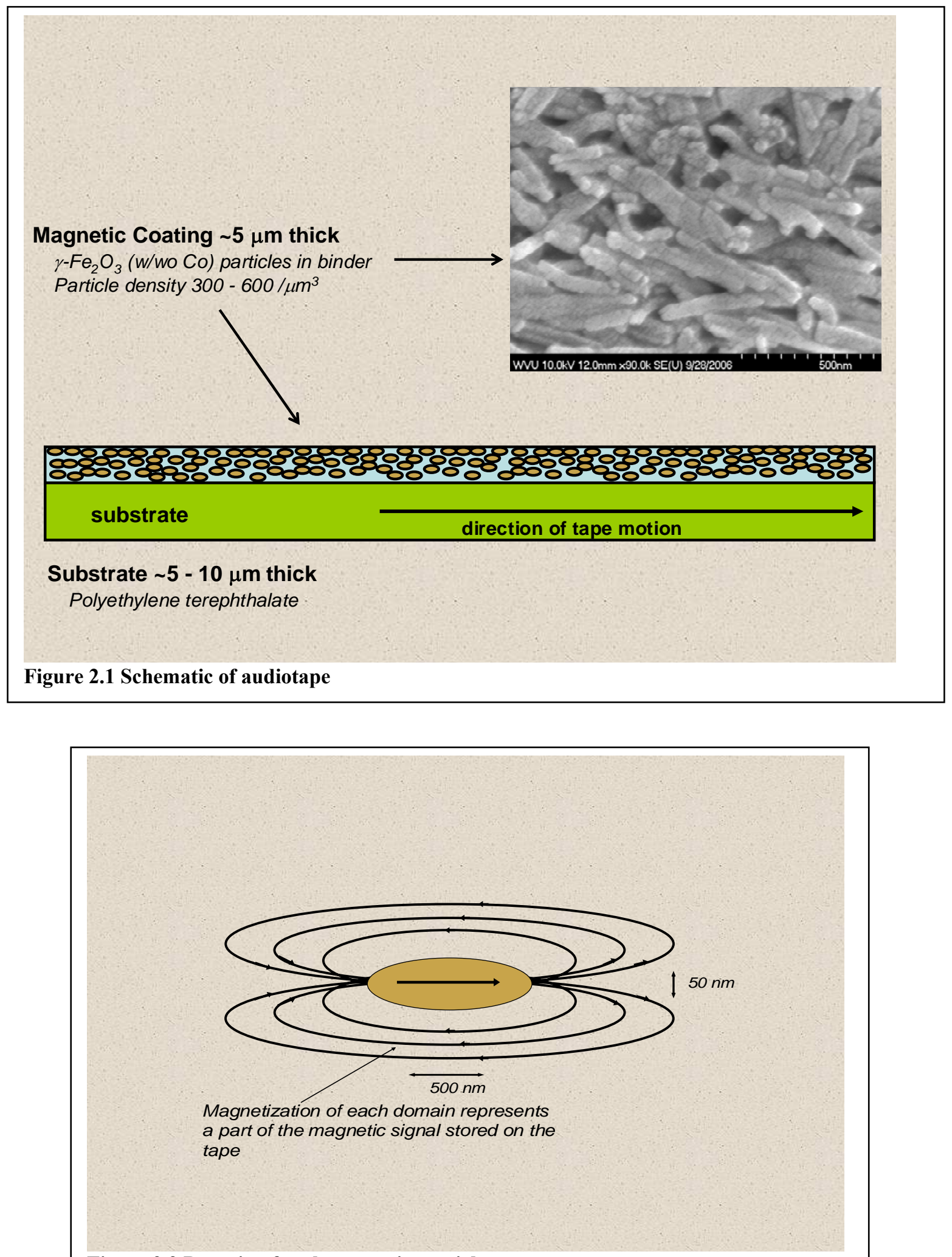

Figure 2.2 Domain of each magnetic particle 
Table 2.1 Magnetic coating materials based on application [5]

\begin{tabular}{|c|c|c|c|c|c|}
\hline Application & Material & $\begin{array}{c}M_{\mathrm{r}}(\infty) \\
\mathrm{kA} / \mathbf{m} \\
\left(\mathrm{emu} / \mathbf{c m}^{3}\right)\end{array}$ & $\begin{array}{c}\mathrm{H}_{\mathrm{c}} \\
\mathrm{kA} / \mathrm{m} \\
(4 \pi \mathrm{Oe})\end{array}$ & $\Delta \mathbf{h}_{\mathbf{r}}$ & $\begin{array}{c}\mathrm{N} \\
10^{3} / \mu \mathrm{m}^{3}\end{array}$ \\
\hline $\begin{array}{l}\text { Reel to reel } \\
\text { audiotape }\end{array}$ & $\gamma-\mathrm{Fe}_{2} \mathrm{O}_{3}$ & $100-120$ & $23-28$ & $0.30-0.35$ & 0.3 \\
\hline Audiotape IEC I & $\begin{array}{c}\gamma-\mathrm{Fe}_{2} \mathrm{O}_{3} \\
\gamma-\mathrm{Fe}_{2} \mathrm{O}_{3}+\mathrm{Co} \\
\end{array}$ & $\begin{array}{l}120-140 \\
120-140 \\
\end{array}$ & $\begin{array}{l}27-32 \\
38-42 \\
\end{array}$ & $\begin{array}{l}0.25-0.35 \\
0.25-0.35 \\
\end{array}$ & $\begin{array}{l}0.6 \\
1.4 \\
\end{array}$ \\
\hline Audiotape IEC II & $\mathrm{CrO}_{2}$ & $120-140$ & $42-52$ & $0.25-0.35$ & 0.6 \\
\hline Audiotape IV & $\mathrm{Fe}$ & $230-260$ & $80-95$ & $0.30-0.37$ & 3 \\
\hline $\begin{array}{c}\text { Professional Video } \\
\text { Tape }\end{array}$ & $\begin{array}{c}\mathrm{Fe} \\
\mathrm{CrO}_{2} \\
\gamma-\mathrm{Fe}_{2} \mathrm{O}_{3}+\mathrm{Co}\end{array}$ & $\begin{array}{c}240 \\
110 \\
90\end{array}$ & $\begin{array}{c}110-125 \\
42 \\
52\end{array}$ & $\begin{array}{c}0.32 \\
0.3 \\
0.35\end{array}$ & $\begin{array}{c}4 \\
1.5 \\
1\end{array}$ \\
\hline Home Video Tape & $\begin{array}{c}\mathrm{CrO}_{2} \\
\gamma-\mathrm{Fe}_{2} \mathrm{O}_{3}+\mathrm{Co} \\
\mathrm{Fe}\end{array}$ & $\begin{array}{l}110 \\
105 \\
220\end{array}$ & $\begin{array}{c}44-58 \\
52-74 \\
110-125\end{array}$ & $\begin{array}{l}0.35 \\
0.35 \\
0.38\end{array}$ & $\begin{array}{l}2 \\
2 \\
4\end{array}$ \\
\hline $\begin{array}{l}\text { Instrumentation } \\
\text { Tape }\end{array}$ & $\begin{array}{c}\gamma-\mathrm{Fe}_{2} \mathrm{O}_{3} \\
\gamma-\mathrm{Fe}_{2} \mathrm{O}_{3}+\mathrm{Co}\end{array}$ & $\begin{array}{c}90 \\
105\end{array}$ & $\begin{array}{l}27 \\
56\end{array}$ & $\begin{array}{l}0.35 \\
0.50\end{array}$ & $\begin{array}{l}0.6 \\
0.8\end{array}$ \\
\hline Computer Tape & $\begin{array}{c}\gamma-\mathrm{Fe}_{2} \mathrm{O}_{3} \\
\gamma-\mathrm{Fe}_{2} \mathrm{O}_{3}+\mathrm{Co} \\
\mathrm{CrO}_{2} \\
\mathrm{Fe}\end{array}$ & $\begin{array}{c}87 \\
90 \\
120 \\
220\end{array}$ & $\begin{array}{c}23 \\
44 \\
40 \\
110-125\end{array}$ & $\begin{array}{l}0.30 \\
0.33 \\
0.29 \\
0.38\end{array}$ & $\begin{array}{c}0.16 \\
0.8 \\
1.4 \\
4\end{array}$ \\
\hline Flexible Disk & $\begin{array}{c}\gamma-\mathrm{Fe}_{2} \mathrm{O}_{3} \\
\gamma-\mathrm{Fe}_{2} \mathrm{O}_{3}+\mathrm{Co} \\
\text { Ba-Ferrite }\end{array}$ & $\begin{array}{l}56 \\
60 \\
56\end{array}$ & $\begin{array}{l}27 \\
50 \\
58\end{array}$ & $\begin{array}{c}0.34 \\
0.34 \\
0.4\end{array}$ & $\begin{array}{l}0.3 \\
0.5 \\
1.5\end{array}$ \\
\hline Computer Disk & $\begin{array}{c}\gamma-\mathrm{Fe}_{2} \mathrm{O}_{3} \\
\gamma-\mathrm{Fe}_{2} \mathrm{O}_{3}+\mathrm{Co}\end{array}$ & $\begin{array}{l}56 \\
60\end{array}$ & $\begin{array}{l}26-30 \\
44-55\end{array}$ & $\begin{array}{l}0.30 \\
0.30\end{array}$ & $\begin{array}{l}0.3 \\
0.5\end{array}$ \\
\hline
\end{tabular}




\subsection{Erase, Record \& Reproduce Process}

The "recording" device, as shown in Figure 2.3, consists of three magnetic heads.

i) The erase head, ii) the record head and iii) playback head

The erase head applies a high amplitude, high frequency AC magnetic field. The purpose of this is to erase any data already present and to randomize the magnetic orientation of the particle. The erase head is typically wider than the recording head which increases the duration of the stay over this region. This is to ensure complete erasure of the any previously recorded signal. In some basic devices, this head simply consists of a bar magnet.

The record head applies the signal to be recorded along with a high frequency signal called the AC biasing signal. Signal AC biasing is done to ensure the linearity of the recording process.

The reproduce head is the final head over which the audiotape passes. This magnetic field recorded in the audiotape induces an electric current in the head obeying Faraday's law. This induced current is the electric signal which was originally recorded on the tape. In many cases, the record and the playback head are one and the same. The gap size in the erase and record heads determine the orientation and strength of the applied magnetic field as it interacts with the tape. Because of the relative dimensions of the gap and the size of the magnetic particles, the erase, record and reproduce process inherently averages over a large number of magnetic particles. 


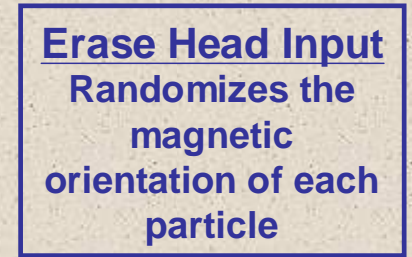
Record Head Input Produces magnetic field which is captured by magnetic particles

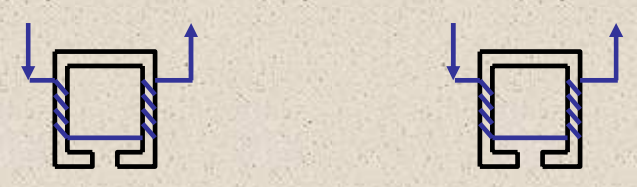

Reproduce Head Output Magnetic field stored in the particles induces an electrical response in the head

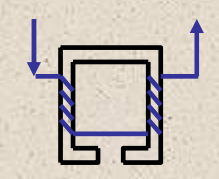

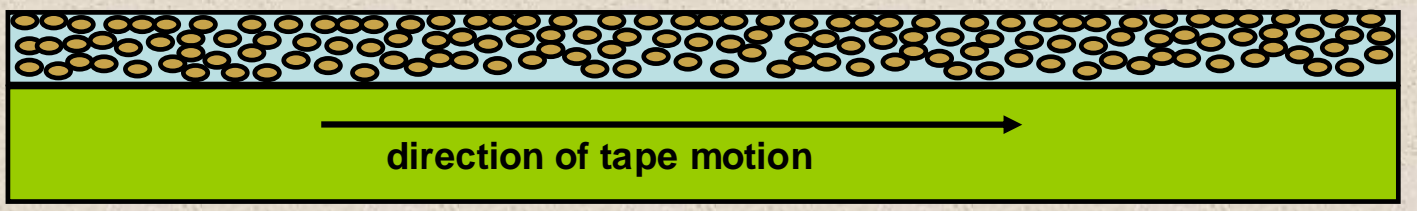

Figure2.3 Schematic representation of the head of an audiotape

\subsection{Data Format}

A pictorial representation of data format is shown in Fig 2.4. On either side of the tape (A or B, referred to as tracks), stereo or mono, data can be recorded. The data format is closely associated with the structure of the tape. There is a buffer layer between the two sides and also between the stereo tracks to avoid any overlapping of information. It is to be noted that the two sides A and B are recorded in the opposite directions. 
Stereo tracks + buffer area (between stereo tracks) covers the same area as one mono track

Buffer areas between recorded tracks

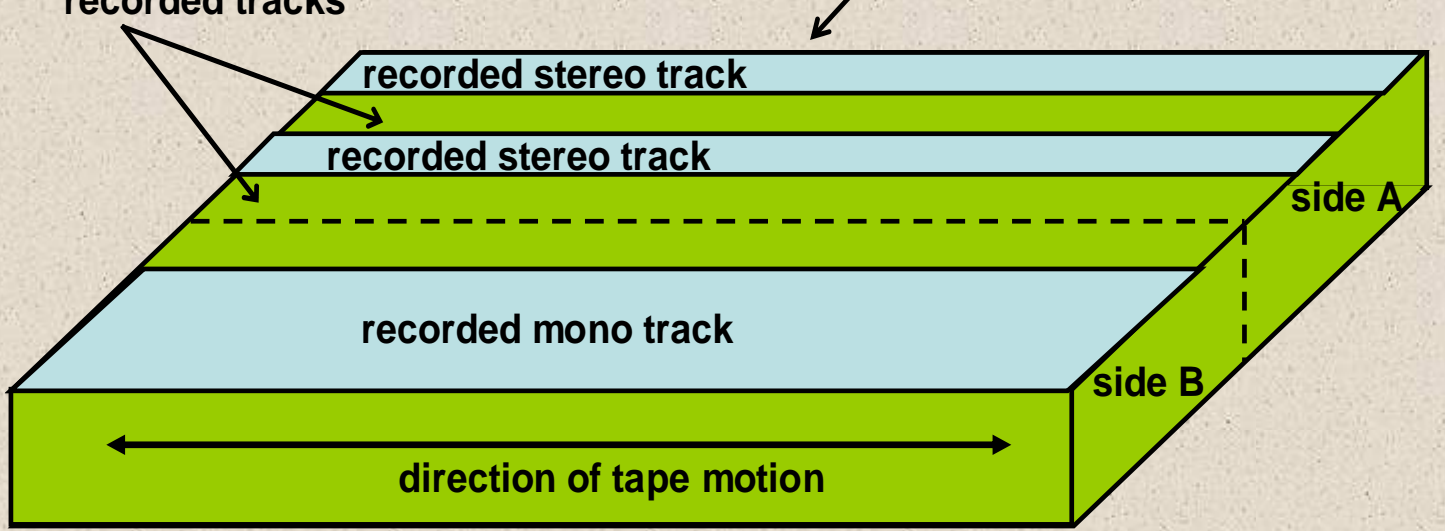

Side $A$ and side $B$ are recorded along opposite edges of the tape with a buffer area in between the tracks

Figure 2.4 Data format of the audiotape 


\section{Chapter 3 Literature Review}

Review of the literature revealed that extracting remnant information from a magnetic medium has previously been addressed using different approaches. It was found that several studies have been performed to investigate magnetization patterns in recording media with sub-micron resolution [3]. These include MFM [7, 8] and magnetic force scanning tunneling microscopy (MFSTM) [9]. These studies focus on analysis of magnetic hard drives. They examine/ detect remnant information left behind because the recording heads are misaligned. To our best knowledge, systematic studies have not been performed for the retrieval of overwritten and erased signals on audiotape using MFM. A technique known as magnetoresistive microscopy (MRM) [2] has been used to reproduce and examine audiotape data for forensic analysis. This technique averages over large numerous of magnetic particles. It therefore does not have the resolution to achieve our goals. It is of interest, however, because of the similarities of the approach to the magnetic media.

Section 3.1 reviews the work of Gomez et al. [3] which deals with the imaging of overwritten data on commercially rigid magnetic disks using (MFSTM). The work of Pappas et al. [2] is discussed in the Section 3.2 which uses MRM to authenticate and recover data from a magnetic storage (tape) media.

\subsection{Imaging of Overwritten Data using MFSTM [3]}

Gomez et al. [3] used magnetic force scanning tunneling microscope (MFSTM) to characterize overwritten hard disk media. In MFSTM, a fixed magnetic probe is held at a small bias potential quite close to the sample surface in such a way that the electrons can 
tunnel through the gap existing between them. As the probe rasters and interacts with the magnetic fields of the surface, the vertical position of the probe is adjusted so as to maintain a constant current flow. This results in the vertical displacement of the probe as a function of position on the disk.

Figure 3.1 shows an MFSTM image of a commercial rigid hard disk with overwritten data. New data or overwritten information appears as larger, bright and dark stripes representing oppositely magnetized regions extending upward from the bottom of the image. At the upper edge of the new data, what appears to be misaligned data can be seen. This is remnant data left behind due to misalignment of the record head. A high resolution image of the overlap between the new and remnant data is shown in Figure

\section{2.}

Remnant information such as that observed by Gomez et al. is interesting but it is not a reliable method of extracting a significant portion of the erased or overwritten data. For that one must extract data directly from the erased or overwritten region. 


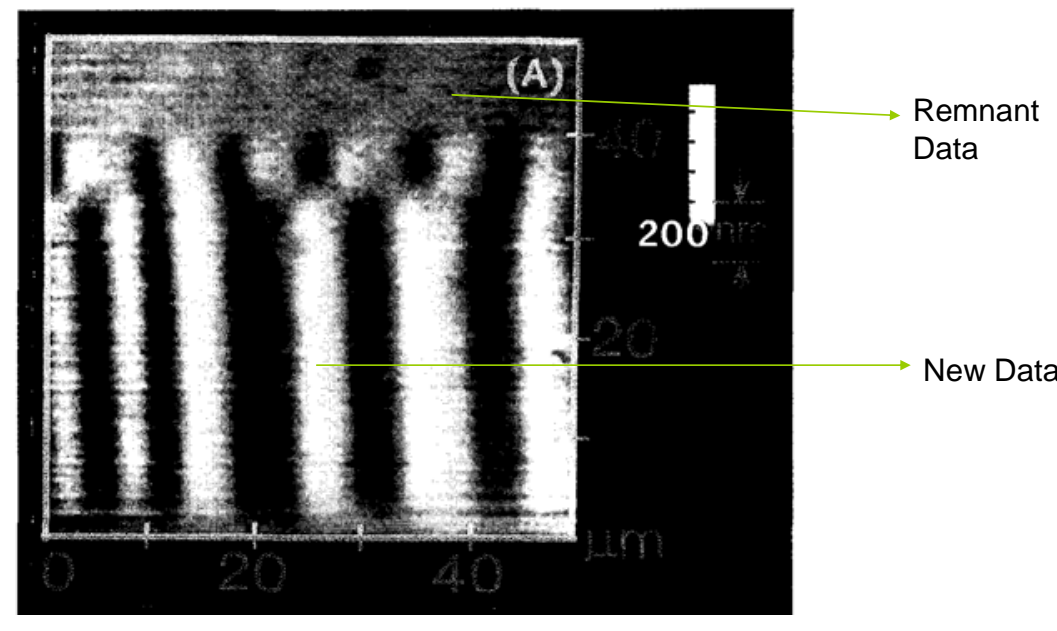

Figure 3.1 MFSTM image of a commercial disk (O1992 IEEE [3]

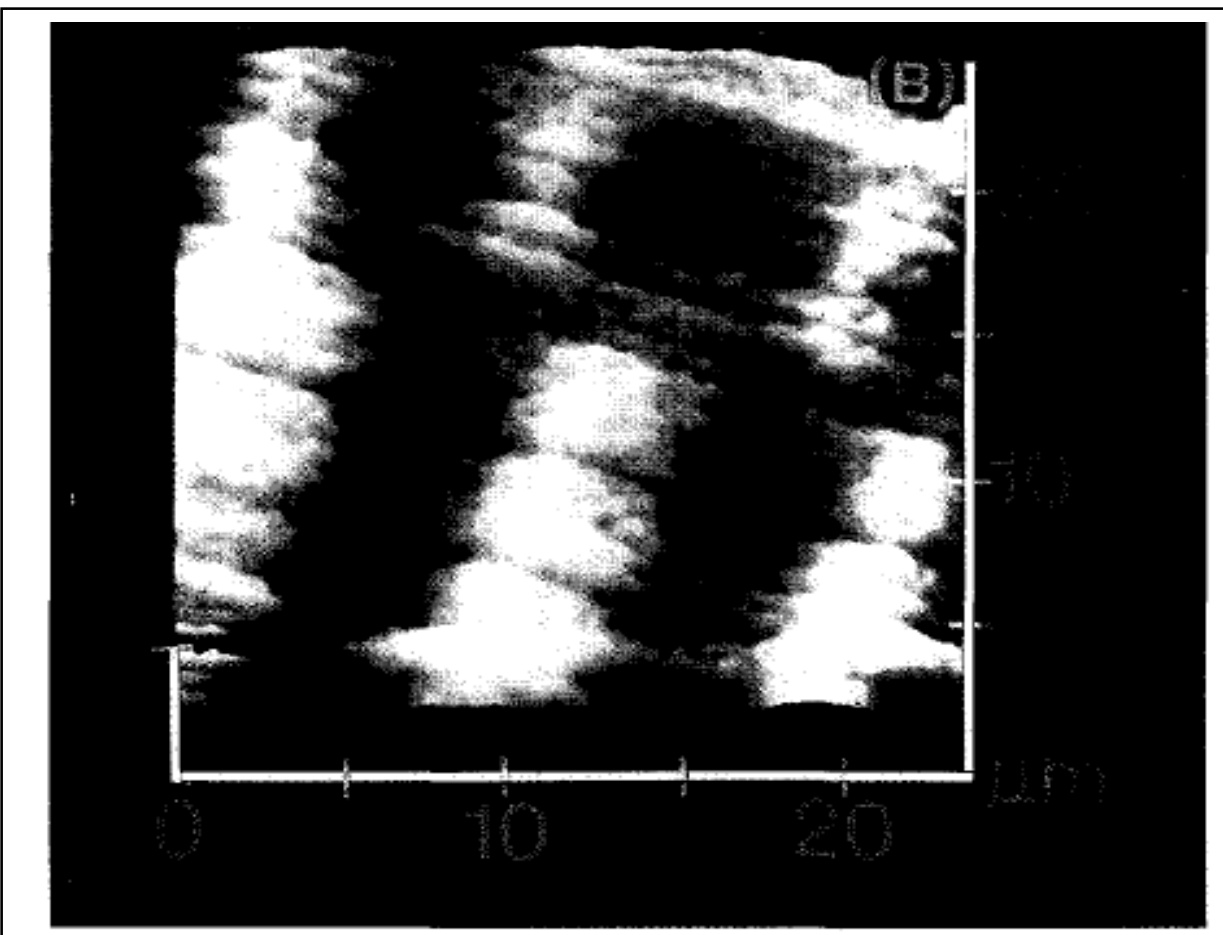

Figure 3.2 MFSTM image of overlapping region (C1992 IEEE [3] 


\subsection{Recovery of analog waveforms using MRM [2]}

Pappas et al. [2] used MRM to image damaged audiotape for forensic analysis. As noted before, MRM averages over large areas compared to MFM. The upper half of Figure 3.3 shows the MRM image of the word "F B I" as extracted from the audiotape. The lower half shows the audio wave (input signal) which was sent from the microphone. An expanded view of the letter "I" is shown in the Figure 3.4. The similarities between both sets of the images are quite apparent.

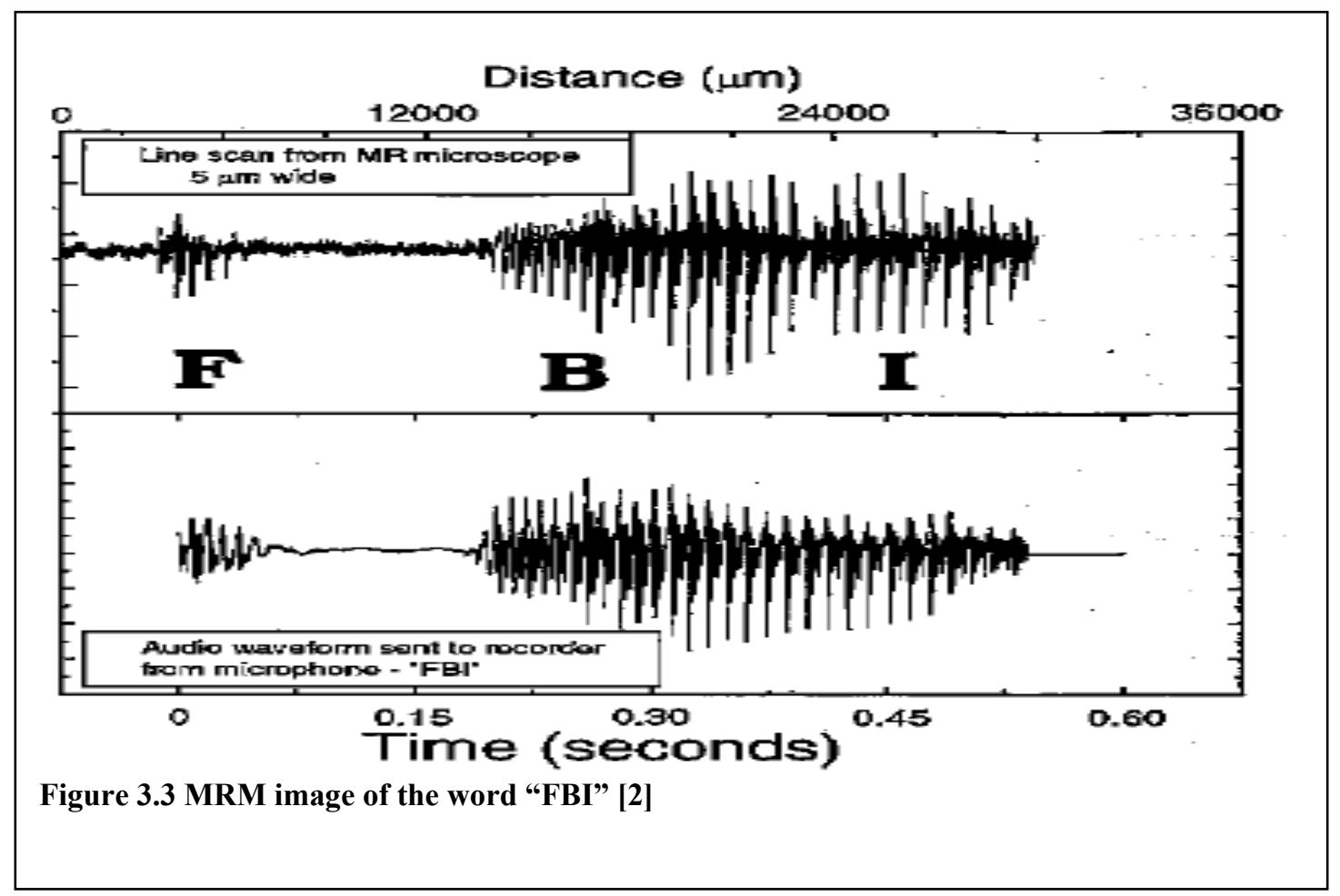




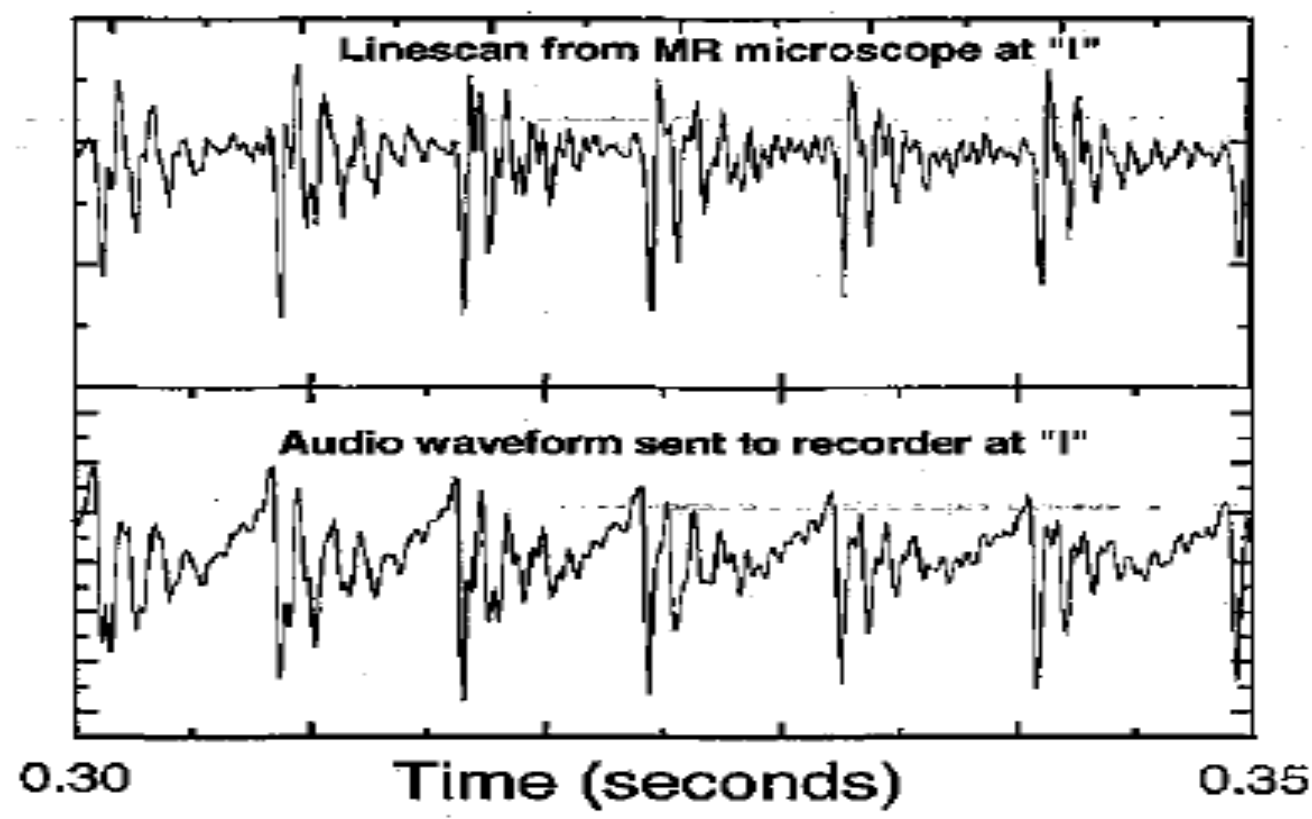

Figure 3.4 Expanded view of the image shown in Figure 3.3 in the region of letter "I" [2]

Pappas et al. also used MRM to image binary data from magnetic storage media. They conclude that additional research is necessary to find out whether the data are altered or not. Though the MRM microscope was successfully demonstrated to image analog and digital data, nothing was said conclusively about the retrieval of altered or erased data. This research confirmed the need for sensors with higher sensitivity and better resolution and also for the recovery of erased or altered data. 


\section{Chapter 4 Experimental Approach}

In order to investigate the possibility data retrieval from an audiotape, it is necessary to utilize a tool that can probe the magnetic image down to the level of individual magnetic domains. One of the only methods to extract this level of magnetic information is magnetic force microscopy, a variant of a broader class of technique called scanning probe microscopy (SPM).

\subsection{Classification of Scanning Probe Microscopy (SPM)}

SPM is a branch of microscopy that images surfaces using a probe or tip (explained in Section 4.2) that scans the surface. The probe is made to move mechanically over the surface, line by line, and the interaction between the probe and the surface is recorded as a function of position. The main advantage of SPM is that it does not require any kind of sample preparation. A classical example is the use of enzyme reverse transcriptase from the AIDS virus to modify the cantilever making it a powerful tool to test new medications capable of inhibiting this enzyme and inactivating the action of the virus [10]. In fact a promising technique mentioned in the work of Pereira is functionalizing the tips or probes in the field of virology [11]. There are many established types of SPM. A simple schematic of the broad division of SPM is shown in the Figure 4.1. This division is based on the work of Gernot Friedbacher et al. [12].

In general SPM images various interactions simultaneously. The manner in which it is used to obtain a particular image denotes the type of operation. Basically SPM is divided into scanning tunneling microscope (STM) and Atomic Force Microscope (AFM). In STM, a small conducting probe is scanned over the sample surface at a close

distance (8-10 $\AA)$. The variations in the tunneling current reflect the topography of the 
surface. STM is further classified into magnetic tunneling, electron stimulated, etc. based on the mode of generation of current. On the other hand, AFM is classified based on the mode of operation: Contact mode where the tip is very close to the surface and Acoustic or tip vibrating mode where the tip is above the sample by a distance of several hundreds of angstroms. In the acoustic or vibrating mode, the tip is allowed to oscillate at its resonance frequency and the change in frequency due to the force exerted by the sample on the probe is measured as a function of position. One of the most important techniques under the non-contact mode ( $\mathrm{NC}$ mode), which is also the one used for this research work is the magnetic force microscopy (MFM). The magnetic force microscopy is explained in detail in the Section 4.4 .

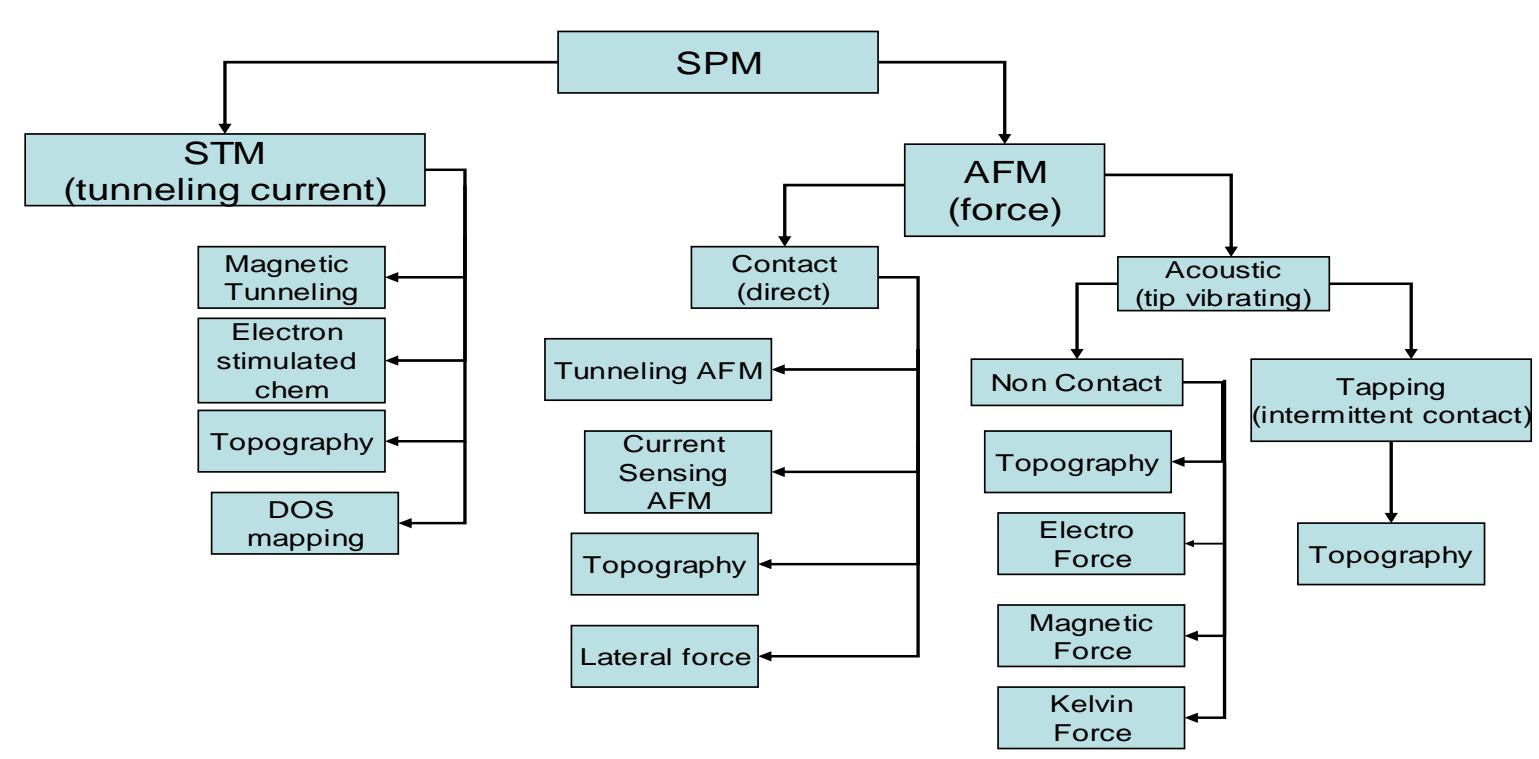

Figure 4.1 Schematic of classification of SPM 


\subsection{Magnetic Force Microscopy}

\subsubsection{Principle}

Magnetic force microscope is essentially an atomic force microscope (AFM) operating in non-contact (NC) mode. The AFM consists of a cantilever with a sharp tip attached to its end. The tip grazes along the sample surface and the deflection of the cantilever due to the force of the sample is measured using the laser spot which is reflected from the top of the cantilever into the photodiode. The interactive force between the sample and probe can be either repulsive or attractive. The force interaction variation with the tip-to-sample separation is similar to Lennard-Jones potential energy curve as shown in Figure 4.2 [13].

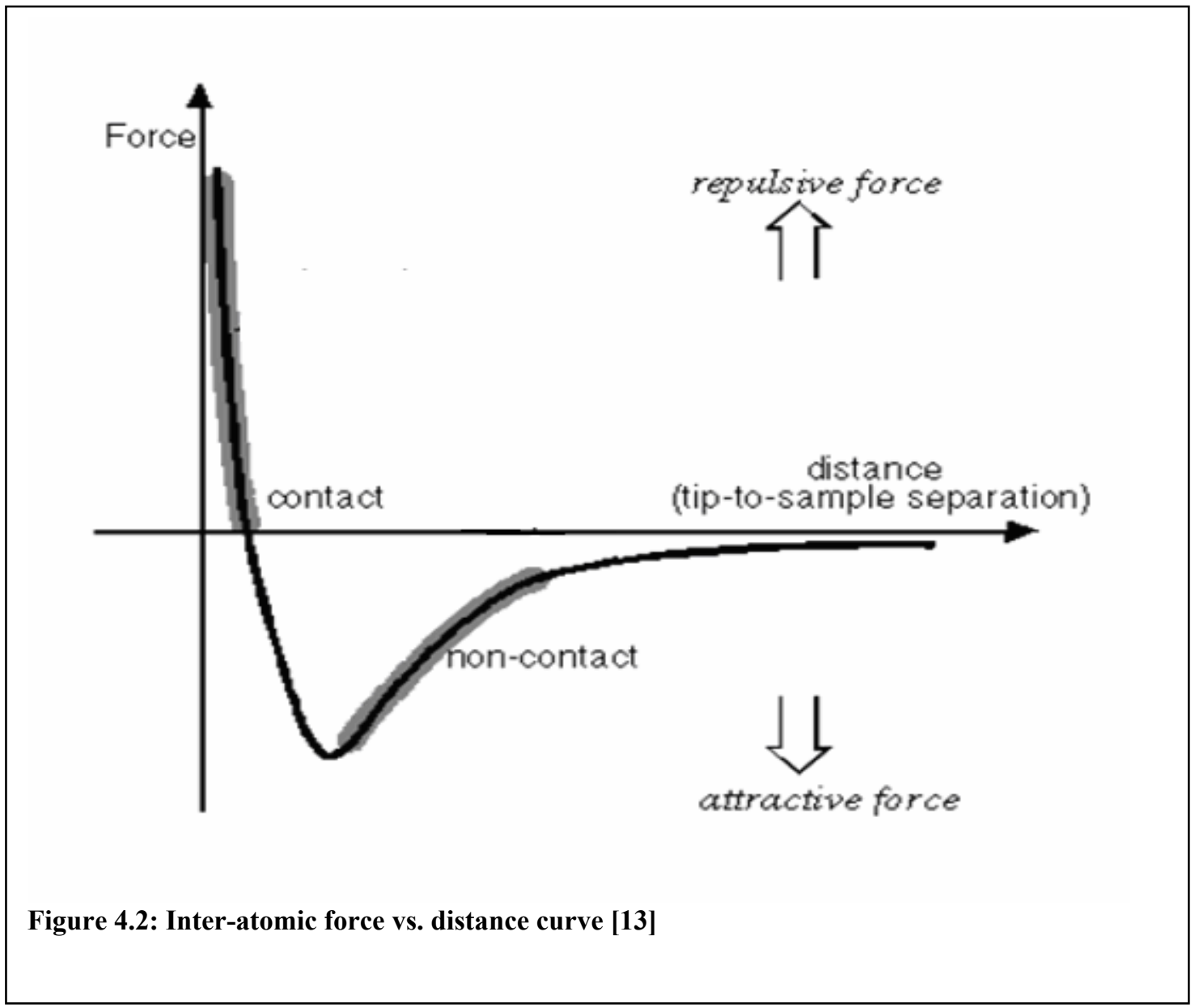


Two very clear-cut regions can be seen from the Figure 4.9. When the overall force of interaction is positive or repulsive, the tip is kept close to the sample surface. This would also avoid the chance of the tip colliding with the surface. Consequently, the force between the tip and the sample is constant during the scanning process. In this mode of operation, the forces of interaction are mainly mechanical (van der Waal) in nature. When the interactive forces are negative or attractive, the tip-to-sample separation is of the order of hundreds of angstroms. This is what is called the 'non-contact' mode in the AFM operation and the force of interaction includes capillary force, electrostatic force etc. When the tip and the sample are magnetic in nature, the predominant force is the magnetic force and the setup becomes MFM.

The NC mode is extremely useful in imaging materials whose elastic moduli are very low. Since the tip does not graze over the surface actually, they do not disturb the atomic features. Hence they are predominantly used in soft polymers, biological materials etc. Also the chances of breakage of the tips are greatly reduced because there is no physical contact between the tip and the sample, resulting in reduced stress on the tip. However, the resolution of the image in contact mode is expected to be quite high compared to the $\mathrm{NC}$ mode as the tip experiences greater force from the sample.

\subsubsection{System Operation}

The working aspect of MFM is fairly simple. It images the surface of the sample by moving a probe across the sample surface thereby measuring the magnetic forces of interaction between the sample and the probe. The probe has a sharp magnetic tip mounted at its end which is used to scan the surface of the specimen. The typical radius of curvature of the tip varies from 3 to $50 \mathrm{~nm}$ [14]. When the tip is brought in close 
proximity of the sample surface, magnetic forces lead to the deflection of the cantilever. Now as the tip moves across the sample, it induces a change in the resonance frequency of the cantilever. The mapping of this change in frequency results in the MFM image.

The system operates in the non-contact mode which means that the probe is usually held at a height of a several hundred nanometers above the surface of the sample. The height at which the tip is placed is called the "Interleave Height" or simply "Lift Height". The net force is the result of the magnetic interaction between the magnetized tip and the magnetic domain of the substrate as shown in Figure 4.3 [15]. This net magnetic force depends heavily on the tip-sample separation or the 'interleave height'. This in turn affects the quality of the image produced. This relationship between image quality and interleave was studied in detail as a part of this research. The interleave height used for this research was $200 \mathrm{~nm}$. The reason for this particular value is justified in the results section.

It is important that the interleave height be greater than the highest features of the surface topography, if not the probe could actually crash into the sample surface. In order to maintain a constant interleave height throughout the experiment, the tip is usually pulled away from the sample by a value well above the interleave height and then brought back to the level of interleave. This particular value of pulling away from the sample is called as "Pullaway Height". The pullaway value used for this research was $400 \mathrm{~nm}$, while interleave heights of $100 \mathrm{~nm}, 200 \mathrm{~nm}$ and $300 \mathrm{~nm}$ were used. 


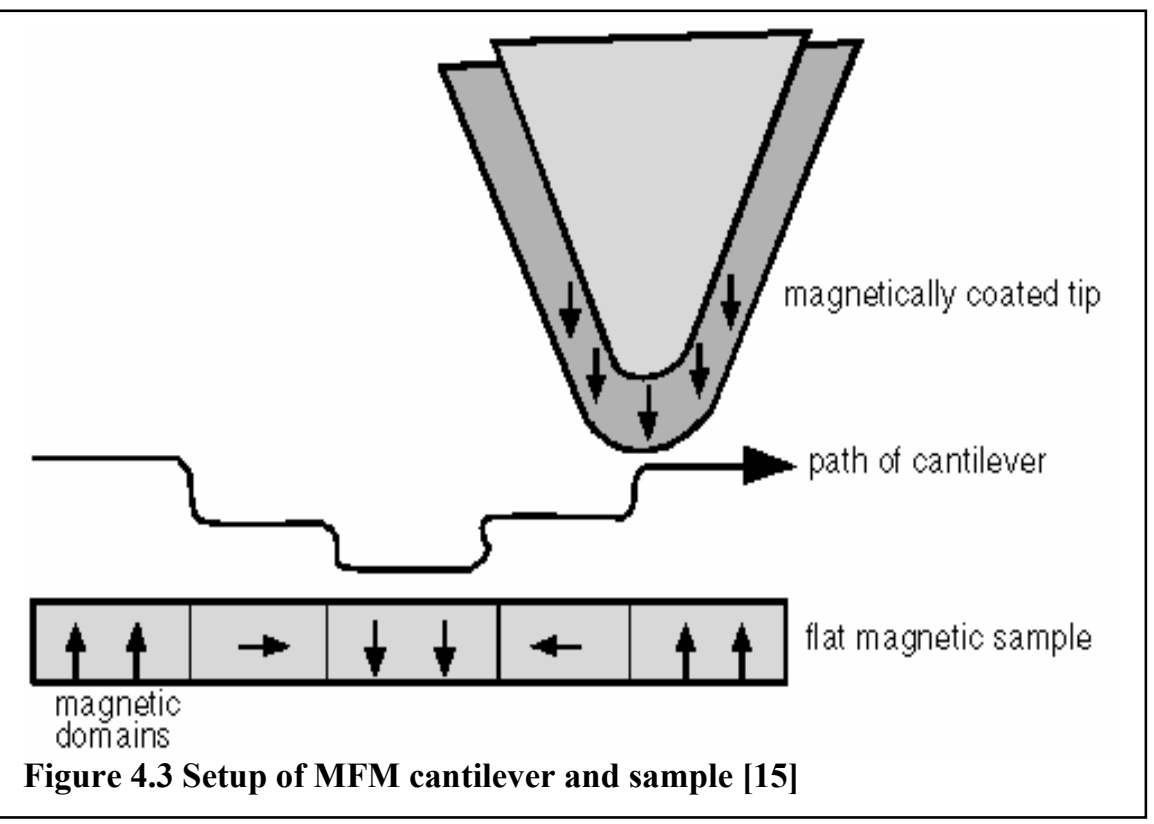

\subsubsection{Magnetic Force Microscopy Setup}

The MFM basically consists of six components. They are laser, MFM tip, scanner, photodiode and a computer. There are many ways to assemble these components. The basic and most common MFM set up looks like the one shown in Figure 4.4 [13]. 


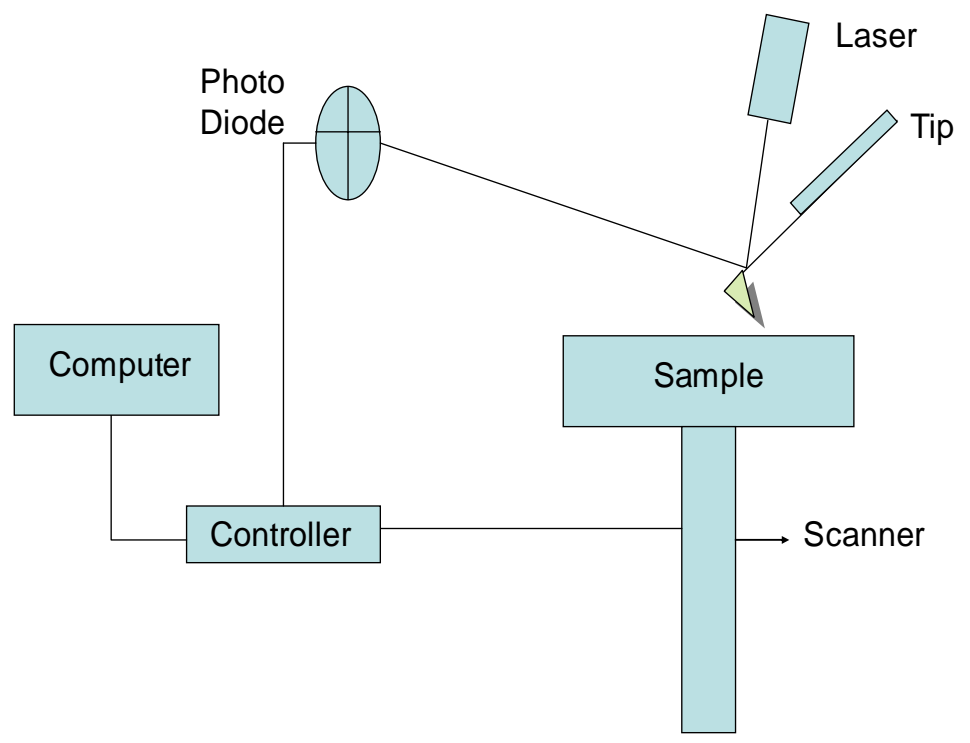

Figure 4.4 Schematic of Magnetic Force Microscopy [13]

The most important component of MFM set up is the magnetic tip which senses the sample. The tip acts as an interface between the sample and the instrument. These tips are attached to a wider piece for support called the cantilever. The tips and the cantilevers come in various shapes and sizes. The next important part of the MFM setup is the scanner. The work of the scanner is to either move the tip across the sample or to move the sample. The most common type of scanner is the piezo-electric scanner which moves the sample under the tip. The controller monitors the movement instructions of the scanner. The computer system which collects the data from the photodiode sends the instructions to the controller. 
As the motion of the scanner is non-linear, non-linear patterns also enter the data, especially during the scans of large areas. This is mainly due to the non-linear response of the piezo-electric current to the applied voltage. This problem is handled by fitting the non-linear curve and the flattening the image using the software. However over fitting the curve can also lead to loss of vital data. The procedure for the operation of MFM is given in Appendix A.

\subsubsection{Mathematical Representation}

As described earlier, the principle behind the working of MFM is the detection of magnetic force gradient of the oscillating cantilever. The cantilever oscillates at a resonance frequency, say $\omega_{0}$. When the tip is subjected to an external magnetic force, there is a shift $(\Delta \omega)$ in the resonance frequency [4]. This leads to a shift in the oscillation phase of the cantilever (referred to as "the phase shift"), denoted by $(\Delta \phi)$. Mathematically, $\Delta \omega$ and $\Delta \phi$ are given by

$$
\Delta \omega=\left(\omega_{o} F^{\prime} t i p\right) / 2 k
$$

$$
\Delta \phi=\left(Q F^{\prime}{ }_{\text {tip }}\right) / k
$$

where $k$ is the spring constant of the cantilever, $\mathrm{Q}$ is the quality factor given by

$$
Q=\omega o / 2 \gamma
$$

and $\mathrm{F}^{\prime}$ tip is the normal component of the magnetic force gradient.

$$
F_{\text {tip }}^{\prime}=d F_{\text {tip }} / d z
$$


The force $\mathrm{F}_{\text {tip }}$ itself is given by

$$
F_{\text {tip }}=\bar{m} \cdot \nabla \bar{H}_{\text {sample }}
$$

Where $\mathrm{m}$ is the effective magnetization of the tip and $\mathrm{h}$ is the stray magnetic field from the sample, $\mathrm{Q}$ is the quality factor, $\omega_{\mathrm{o}}$ is the frequency of oscillation while running freely and $2 \gamma$ is the frequency range bounded by the points on the resonance curve at which oscillation amplitude has dropped by a factor of $1 / \sqrt{2}$ of the maximum amplitude. An important point to be noted is that the shift in the oscillation phase is a function the movement of the tip. The phase shift $(\Delta \phi)$ is taken as the MFM image.

The photo of the MFM instrument used for the purpose of this research is shown in Figure 4.5 (manufactured by Agilent Technologies formerly Molecular Imaging, product name: $5500 \mathrm{SPM})$. The MFM rests on the flotation table to minimize external vibrations. This is to ensure that the cantilever vibrates at the resonant frequency. Also the entire assembly is encased in an acoustic isolation chamber to minimize external disturbances on the tip. 


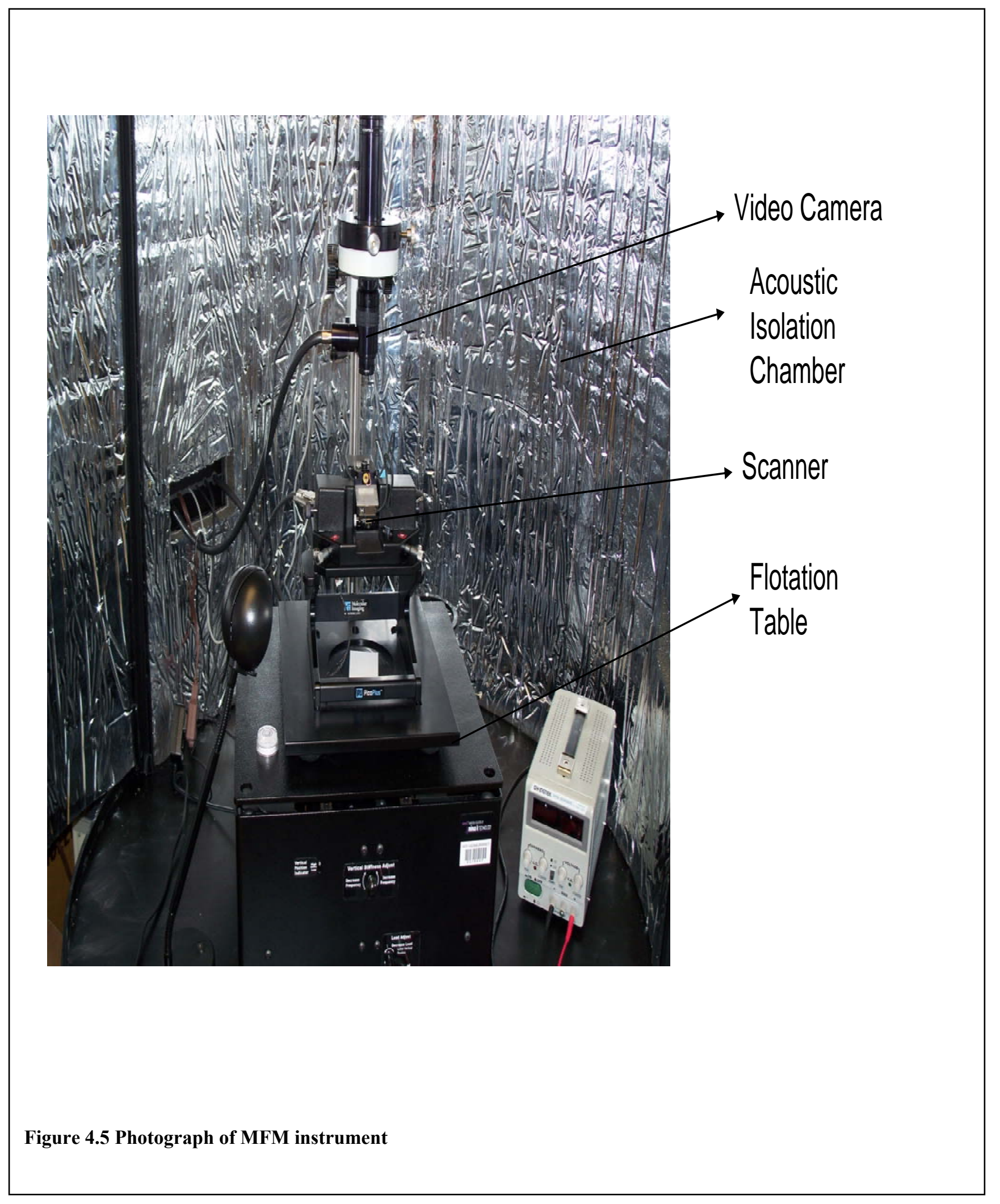




\subsubsection{Scanning Probes or Tips}

The scanning probe or tip is the most important part of any SPM device [16]. The interface between the sample and the probe is the force acting between them. Typically the forces vary from anything mechanical to electrostatic depending on the type of probe used. The tips are attached to a wider piece called the cantilever. The cantilever not only holds the tip but also enables the user to fix it on the device.

The cantilever is usually made of silicon or silicon nitride and the radius of curvature of the tips are of the order of nanometers. The wear and tear of the tip varies widely from user to user and the type of application. Typically a single tip for this research was used for about 15 times to scan the samples. The material used for the tip also depends on type of SPM. For the MFM, the tips have to be magnetic in nature. This will enable the tip to detect any magnetic force from the sample onto the tip. All tips vibrate at a natural frequency called the resonance frequency. The tips used for this research were manufactured by the company called NANOWORLD, located in Switzerland. The thickness, length and width were typically $3 \mu \mathrm{m}, 225 \mu \mathrm{m}$ and $28 \mu \mathrm{m}$ respectively. The natural frequency or the resonance frequency of the tips was around 75 $\mathrm{kHz}$. A typical image of a $75 \mathrm{kHz}$ resonance frequency is shown in Figure 4.6 [17].

Because of high sensitivity of the tip, care should be taken to protect them against the external conditions. These include dust, presence of magnetic materials etc. The tips should not be subjected to any extreme condition including humidity. The dampness would affect the frequency of the tip and any major alteration in the resonant frequency will not produce quality scans. This was prevented by preserving them in an air-tight container. 


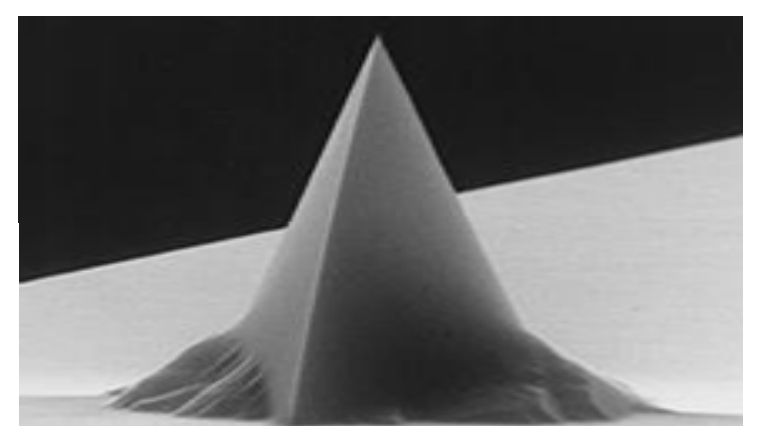

Figure 4.6 Image of SPM probe with frequency of $75 \mathrm{kHz}$ [17]

\subsection{Recording Process}

The recording process of this experiment is fairly simple. A known waveform was generated using the National Instruments signal generator (NI Analog Waveform Editor Version 1.1). This signal was then transmitted to the stereo tape recorder. The wave was then recorded in all the tracks of a virgin audiotape using a standard stereo recording device. The schematic of the recording process is shown in Figure 4.7. The equipment and the model\# used for this purpose are DENON stereo recorder and DRW-585 respectively. The cassette (audiotape) used for this project was low noise (LN) normal bias Type model from RadioShack. It is shown in the Figure 4.8.

In these studies, the input, output and recorded signals were observed using the oscilloscope. An example of the input/output signal of a $5 \mathrm{kHz}$ sine wave of the oscilloscope is shown in Figure 4.9. The input here refers to the signal that comes out of the signal generator board as shown in the Figure 4.7. This output signal represents modifications (distortions in some cases) to the input signal by the circuitry of the 
recorder. This reflects the signal passed to and modified by the recording head.

In studies aimed at retrieving erased data, the signal was identically recorded on both the sides of audiotape. Then one of the sides was purposely erased by recording a blank signal over the previously recorded waveform. Typically, the initial experiments were started with simple waveforms; for example a sine wave of $2 \mathrm{KHz}$. Once the MFM technique was applied successfully, other complex waveforms including square and sawtooth waveforms were also recorded and analyzed.

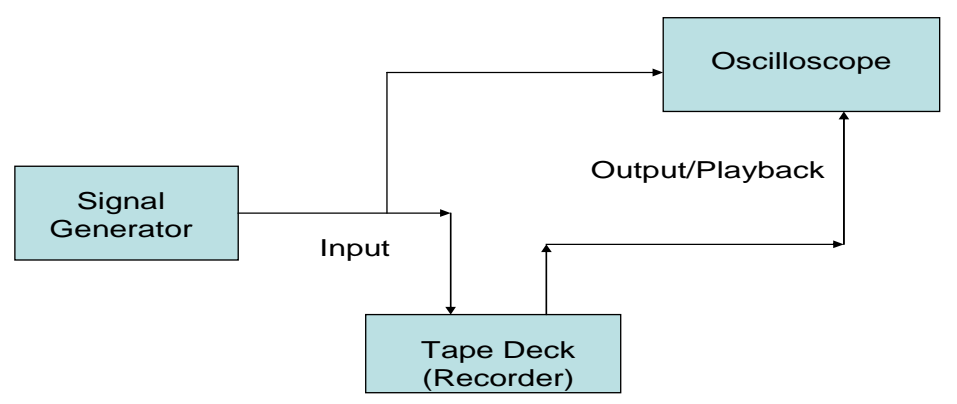

Figure 4.7 Drawing illustrating the recording process setup 


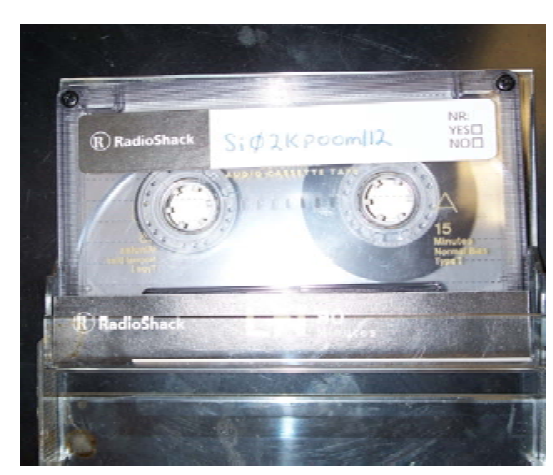

Figure 4.8 Photo of the audiotape

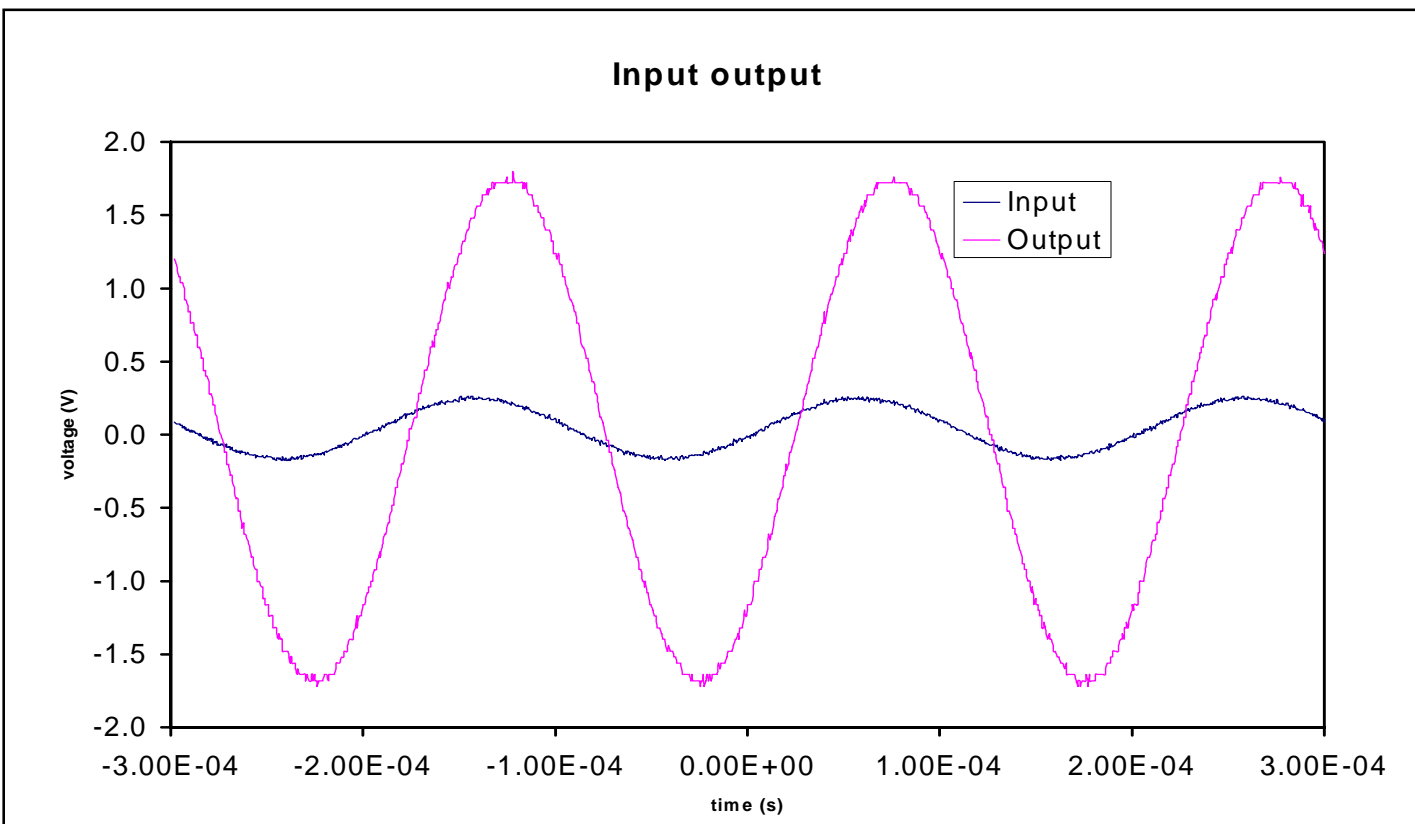

Figure 4.9 Graph of the input/output signal

In order to be able to reproduce the experiment, it was essential that there was no shortage of the quantity of sample (audiotape). Typically the waveforms were recorded 
for a length of about a meter of audiotape. Roughly knowing the spool speed, this was achieved by recording the waveform for a period of 21 seconds. These samples were stored in a moisture free container and the containers were marked with the specific sample name to avoid mixing of samples. This is illustrated in the Figure 4.10. The edges of the tape were also marked to avoid any sort of confusion with the sides of the audiotape. A suitable length of this sample (about an inch) was cut out periodically to fit in the scan stand and then analyzed using MFM technique. The sample struck to the scan stand before placing it underneath the MFM probe is shown in Figure 4.11. (Note that it is extremely important that the sample is stuck flat onto the scan stand to avoid disturbances during the actual experiment. This was done by placing the sample on the scan stand and stretching the tape ends with the help of tweezers and sticking the cellophane at both the ends.)

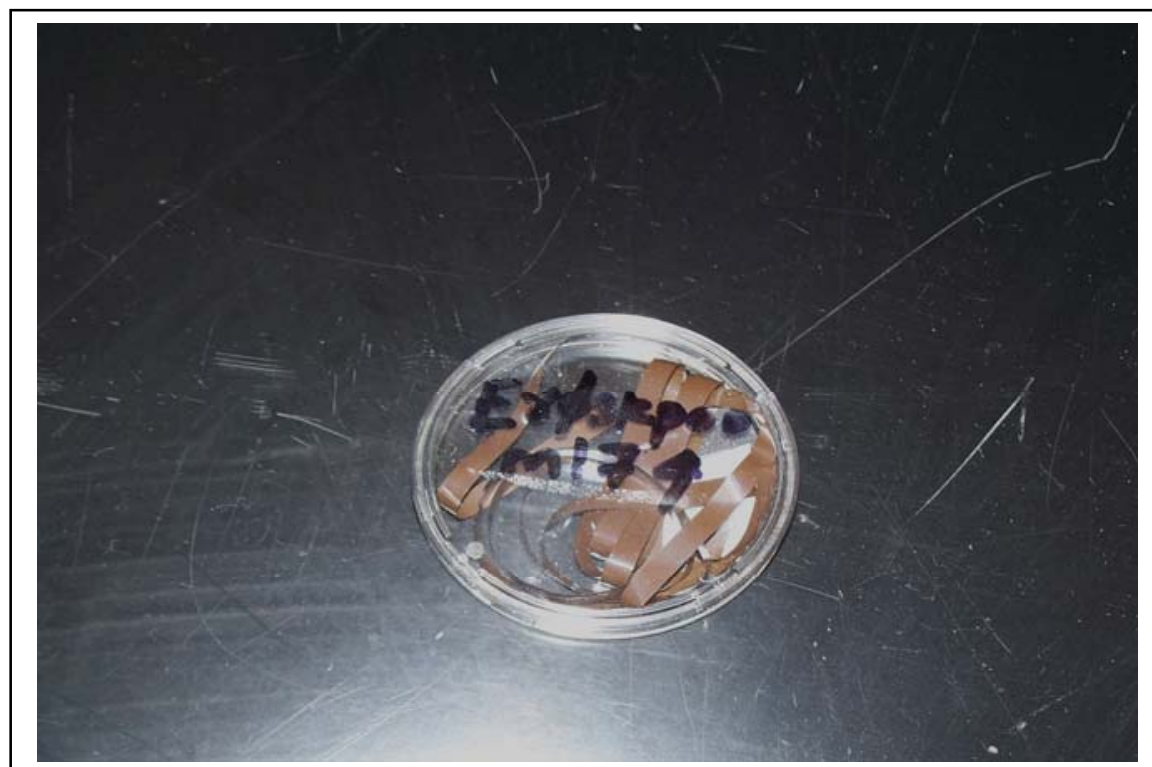

Figure 4.10 Picture of encased recorded audiotape. 


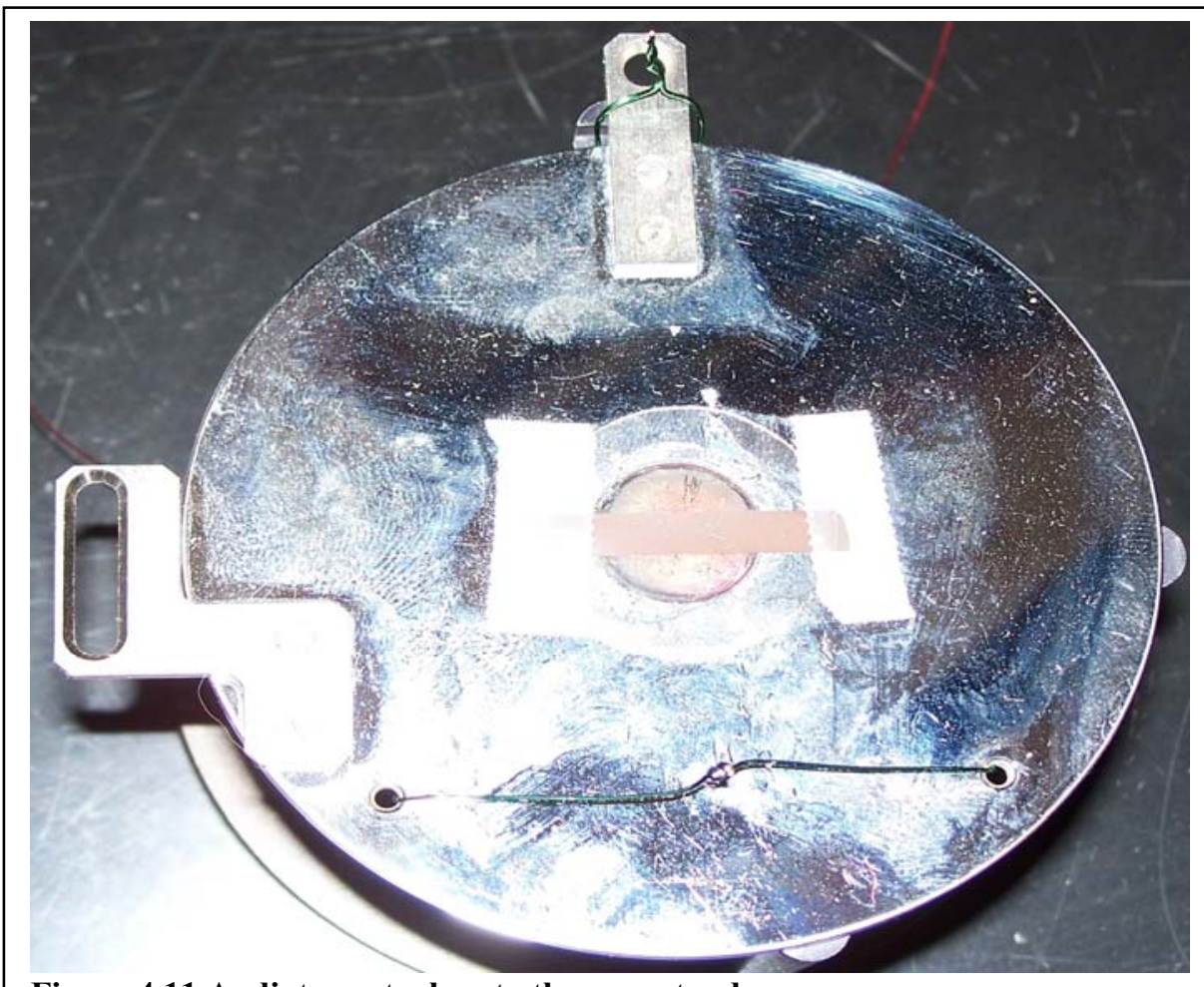

Figure 4.11 Audiotape stuck onto the scan stand

After the recording of waveforms, a simple sketch of audiotape was necessary to keep in track of the different regions that were analyzed. The audiotape was divided into a number of regions depending on the type of study. A typical example is shown in

Figure 4.12.

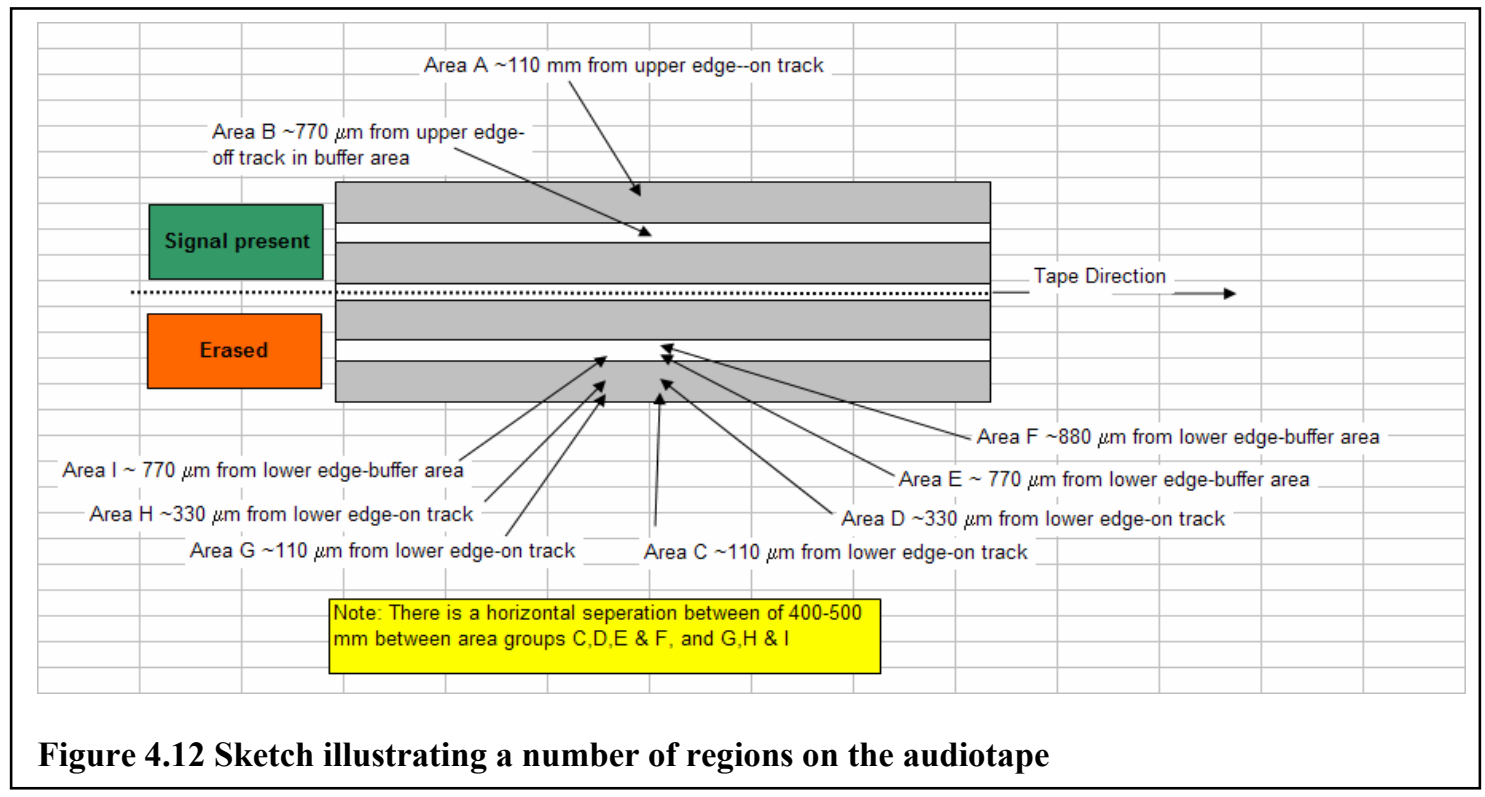




\section{Chapter 5 Results}

The goal of this research is to retrieve data from an altered or erased audiotape using MFM. Having achieved this goal in prior work, the goal of the research is to analyze and optimize key MFM data acquisition parameters. The two key MFM parameters that were considered in this research were

a) Interleave distance

b) Tip speed

Specifically the impact of these parameters on image quality and data recovery time were evaluated and to the extent possible, optimized. Prior to optimization studies, it was necessary to identify specific waveforms which would be recorded and analyzed using MFM. In particular it was important to identify waveforms which could be recorded with a minimum of distortion. To accomplish this, input, output and recorded audio signals were examined using the oscilloscope.

Based on the results which are given in the Section 5.1, the audio signals used in the optimization studies were selected. Section 5.2 gives the result of interleave optimization studies while Section 5.2 gives the results of the tip speed optimization. Experiments were also conducted to find the maximum frequency that could be recorded on the audiotape. These results are given in Section 5.5. Finally the time required to retrieve data from the audiotape using MFM is discussed in Section 5.5.

\subsection{Data Distortion During Recording and Playback}

It was found that the data (signal) was distorted by the recording process itself. Therefore research began by examining various audio signals to determine which signals could be recorded with the least distortion. In this section, examples of different 
waveforms and the associated distortion are given. The recorded signals include square, saw-tooth and sine wave forms.

Figure 5.1 shows an example of a typical square wave input (directly from the signal generation board), output (as modified by the recording electronics) and playback waveforms. In the output signal it is seen that the recording electronics have distorted the leading and trailing edges of the waveform. In the playback signal this distortion is further enhanced. This was initially somewhat disappointing. Since square waves represent the clearest "on-off" audio signals, it was hoped to use this type of signal in the experimental studies.

Figure 5.2 shows an example of a typical saw tooth wave input, output and playback signals. Here it is seen that the distortion is qualitatively less than that for the square wave, but still present. Specifically it can be seen that the wave maximum and minimum are distorted.

Figure 5.3 shows an instance of a typical sine wave input, output and playback signal. Here it is seen that the sine wave is minimally distorted by the recording and the playback operation. For this reason, sine waves were used as the primary test signals in the remainder of the research. 


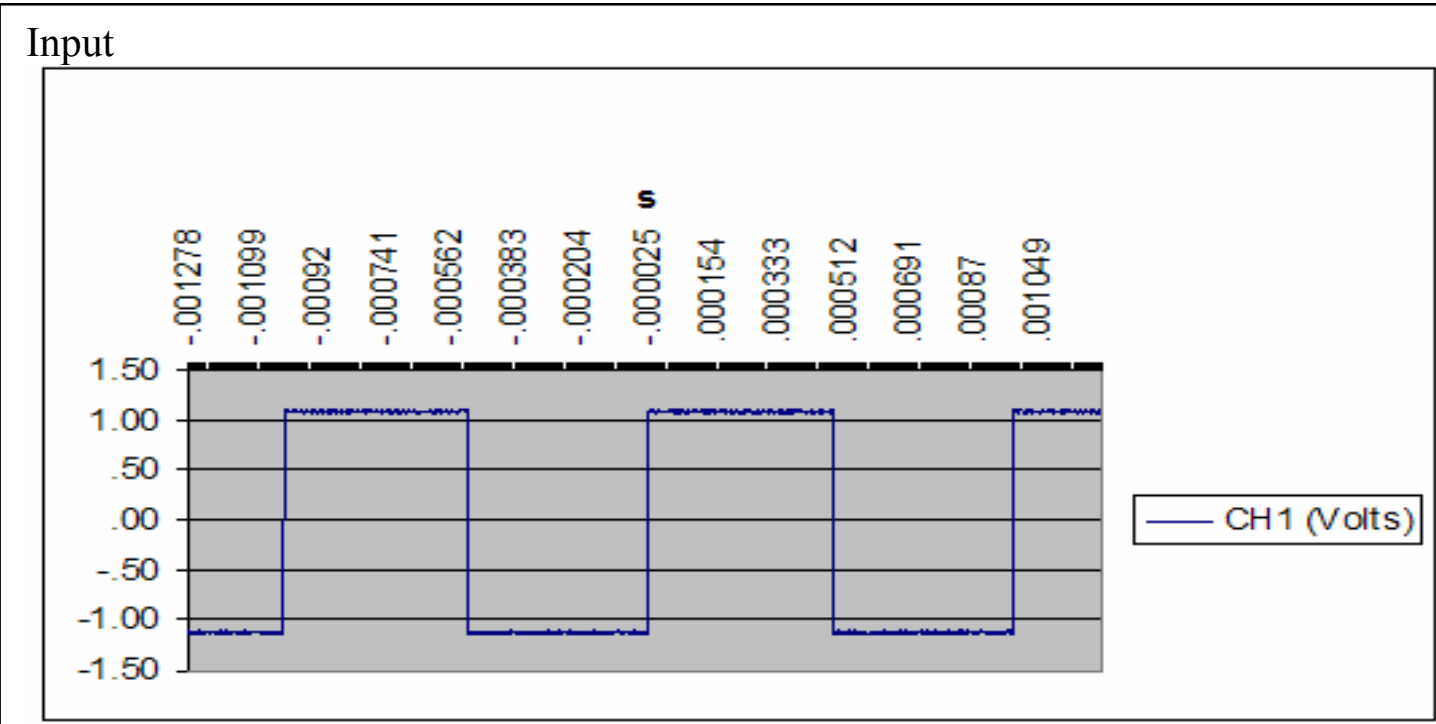

Output

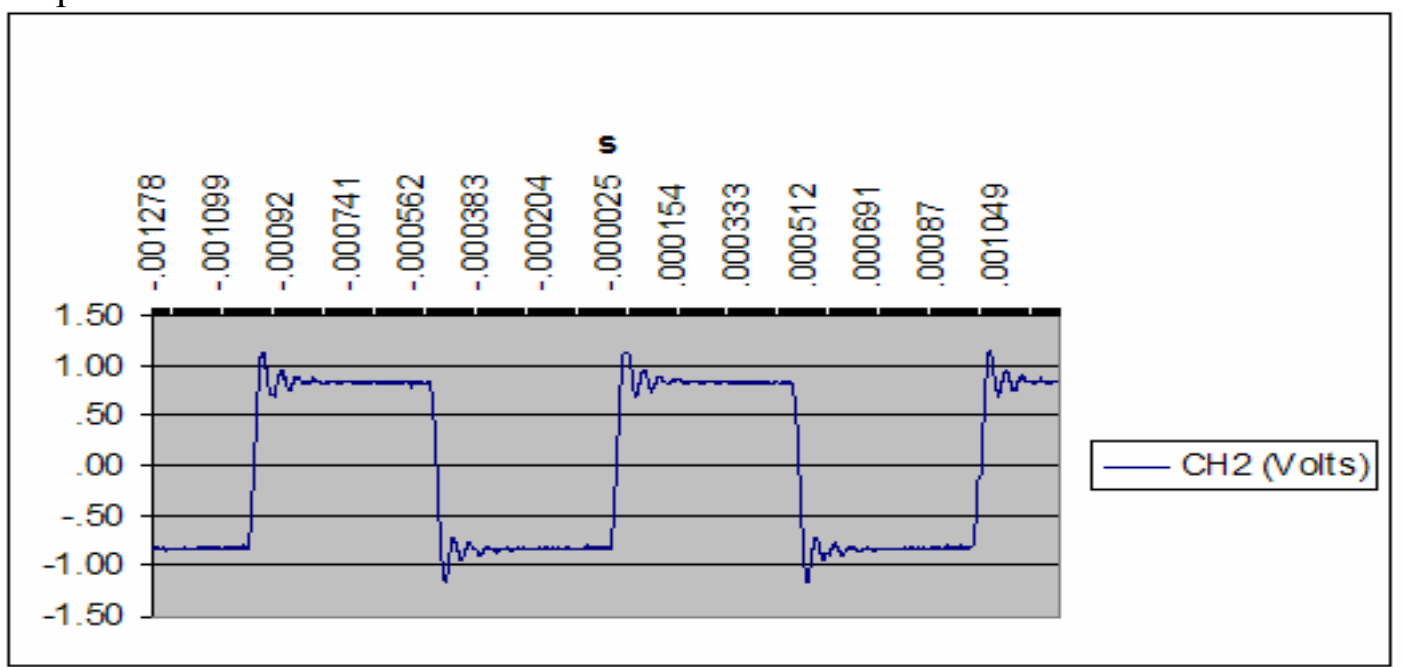

Playback

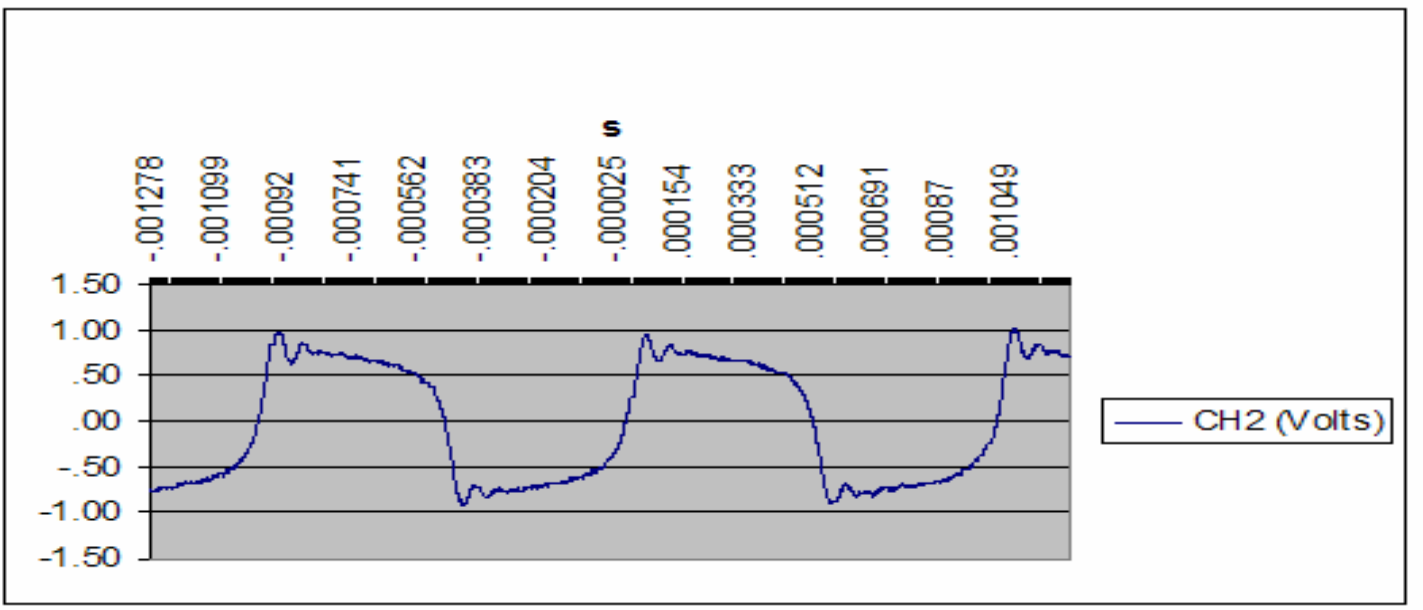

Figure 5.1 Recorded waveform of square wave 


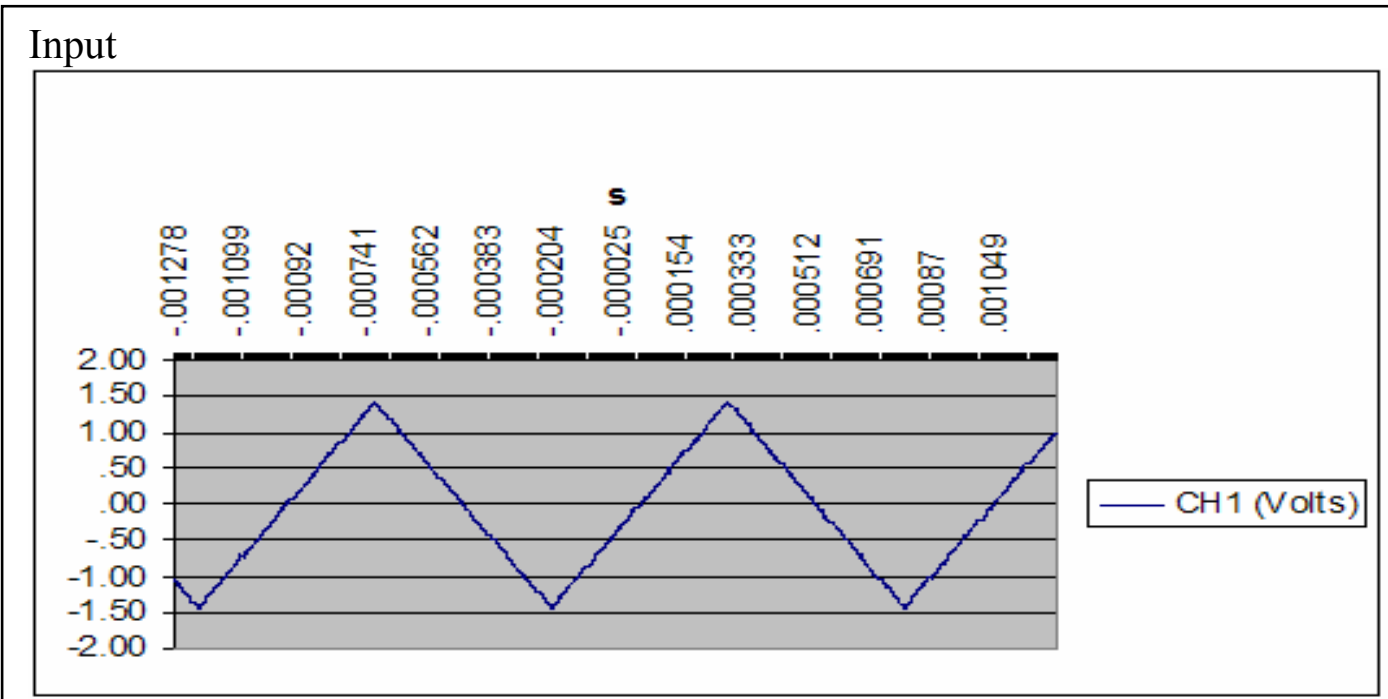

Output

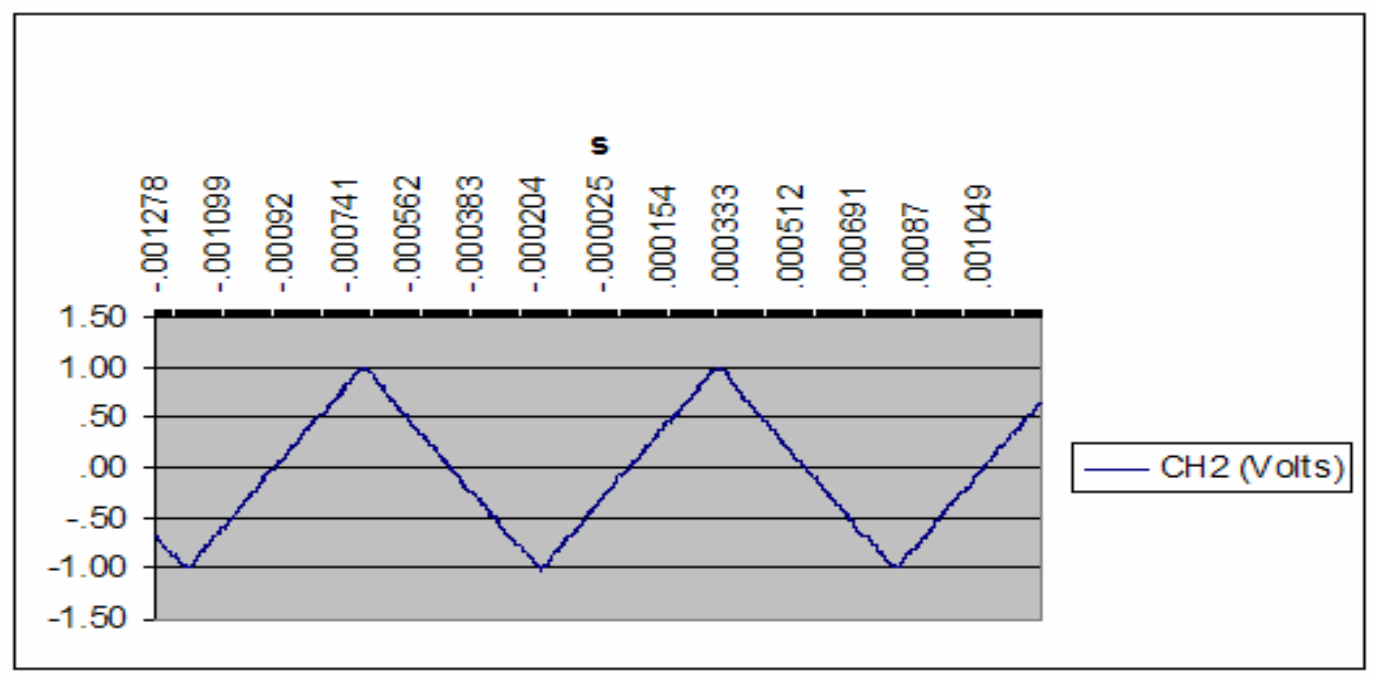

Playback

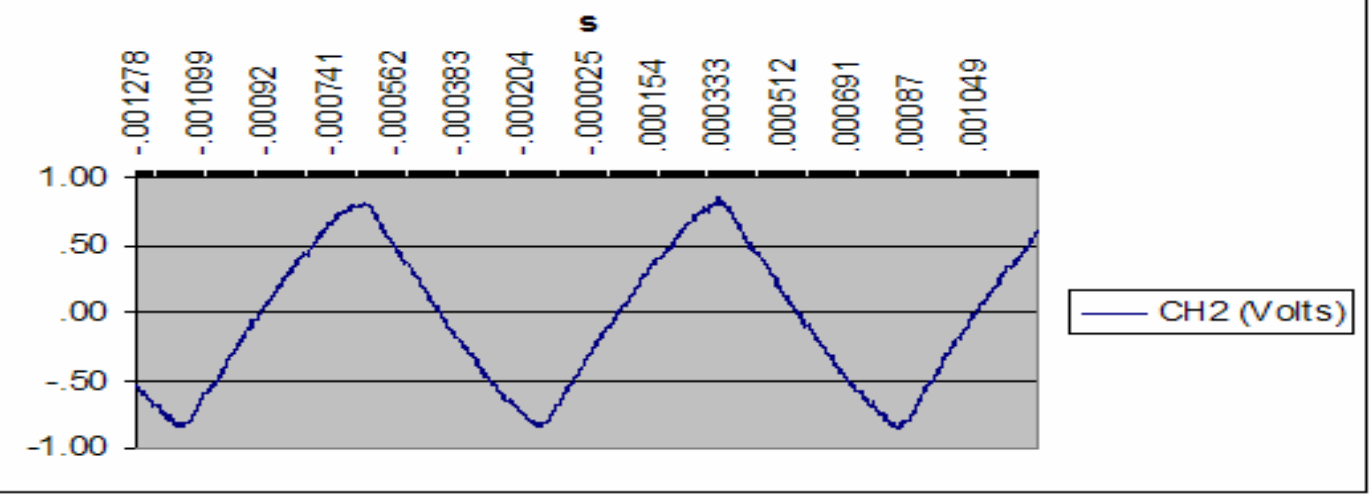

Figure 5.2 Recorded waveform of saw-tooth wave 


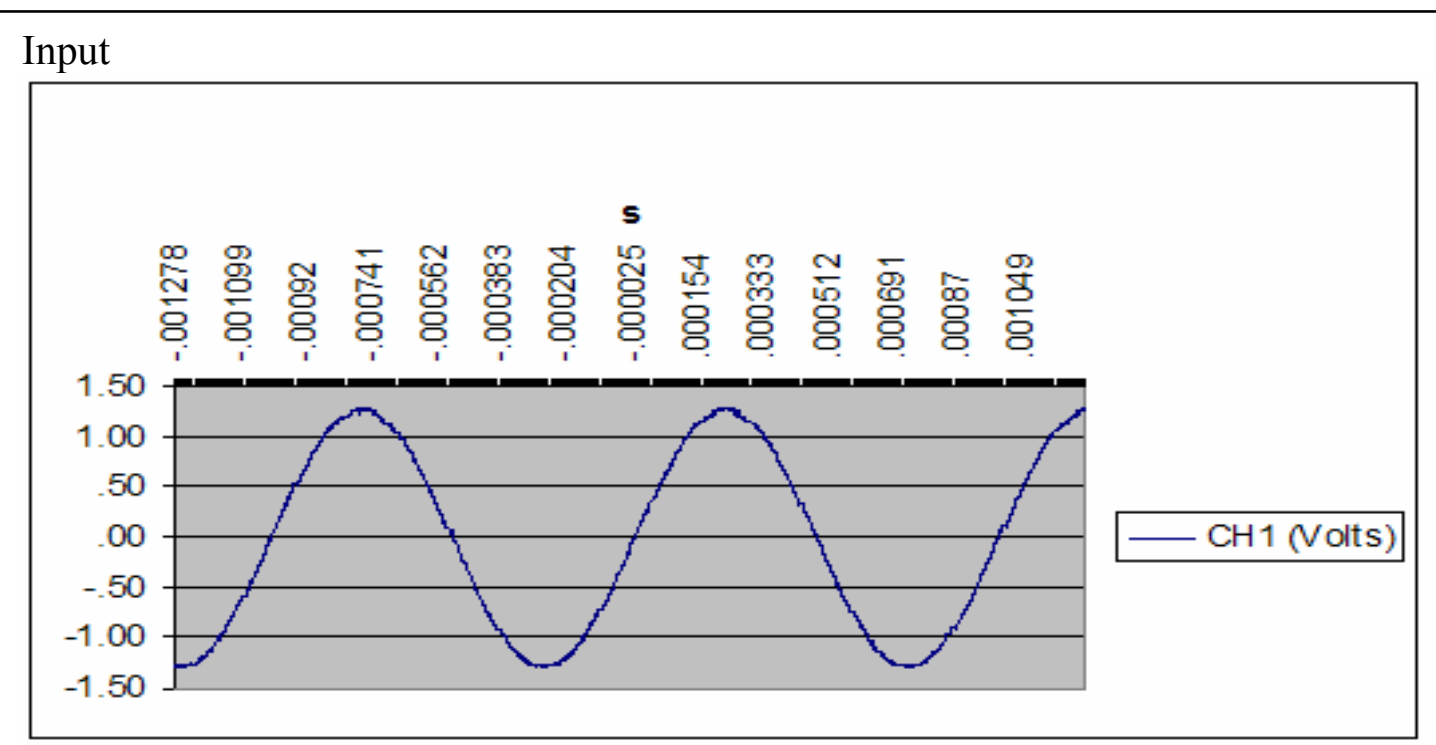

\section{Output}

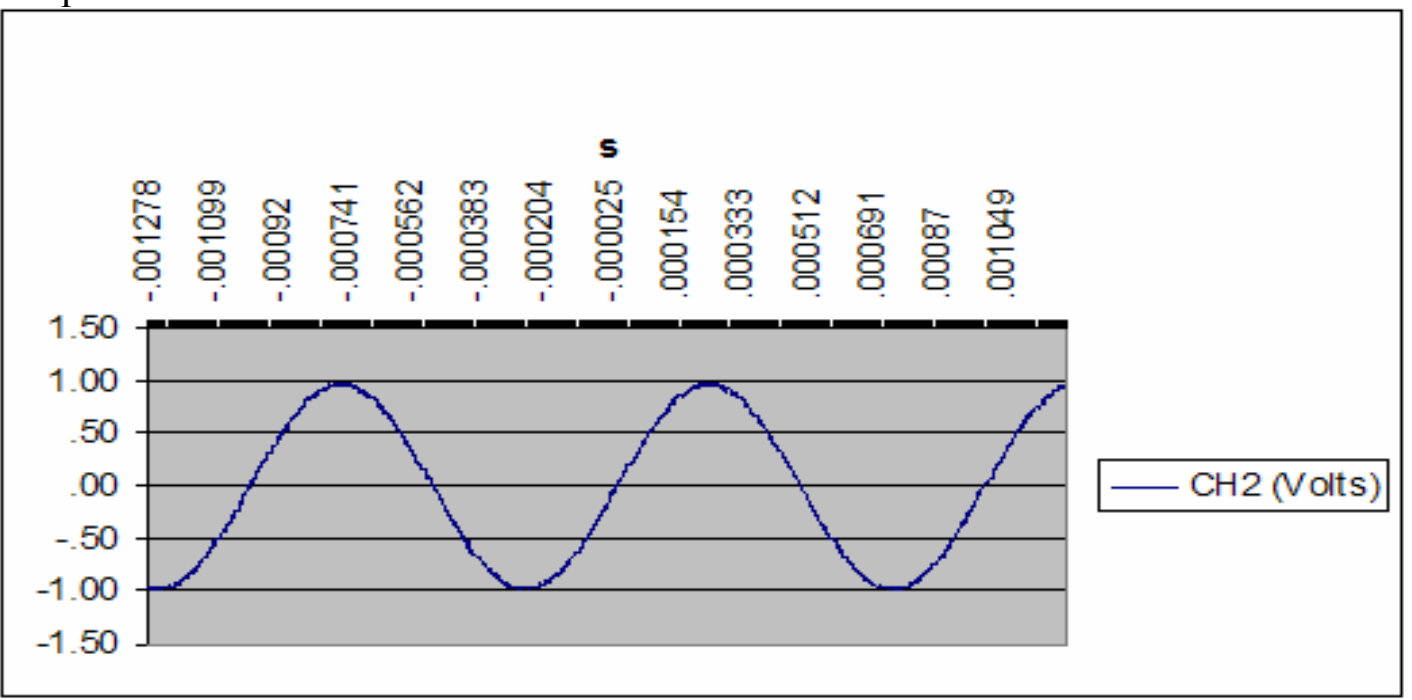

Playback

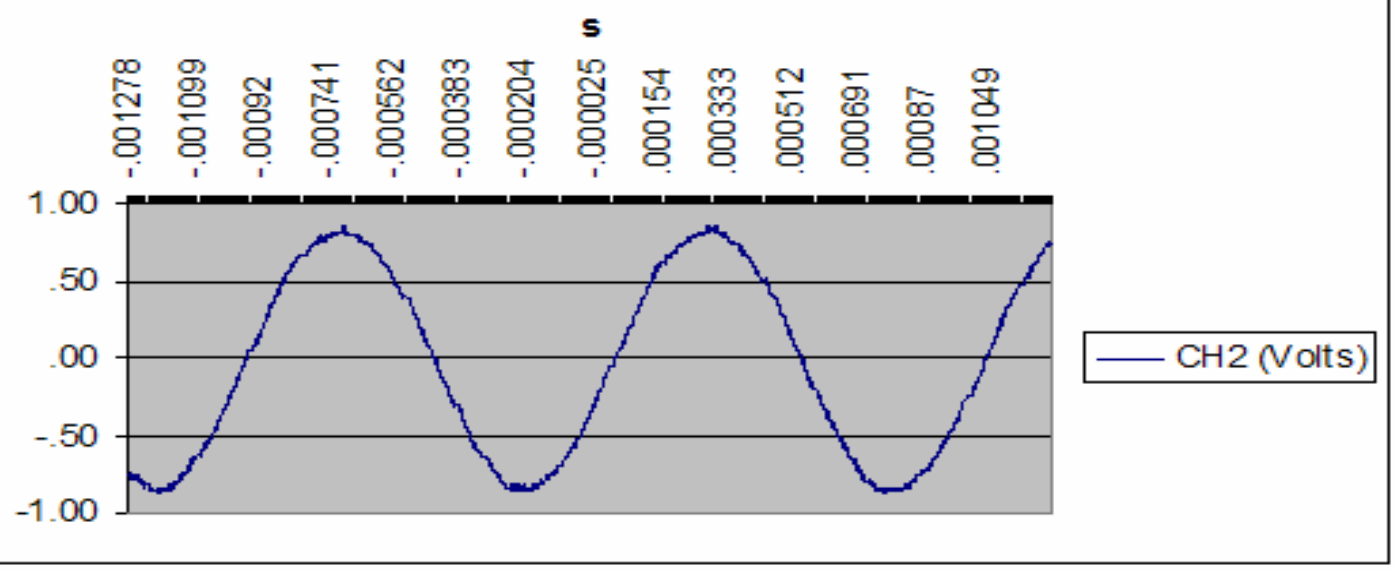

Figure 5.3 Recorded waveform of sine wave 


\subsection{Interleave Height Study}

As stated earlier, two main forces act on the tip by the sample. They are the surface forces due to topography and the magnetic forces of the sample. The relative importance of these forces is strongly influenced by the interleave height. It is necessary to be close enough to the surface to sense low intensity magnetic forces and high enough to be insensitive to the topography forces. If this condition can be met, then the tip or scan speed can be optimized independently as discussed in the next section. For this reason, an early task of this research was to investigate and standardize the interleave height used to collect MFM data. Because the RMS roughness of the tape ranged from 25 $\mathrm{nm}-45 \mathrm{~nm}$, an initial interleave height of 2-4 times this value (100 nm) was chosen. Additional interleave heights of $200 \mathrm{~nm}$ and $300 \mathrm{~nm}$ were also examined.

The input signal for this study was a $2 \mathrm{kHz}$ sine wave. The MFM images of the same area of the audiotape with the recorded $2 \mathrm{kHz}$ signal are shown in the Figures 5.4, 5.5 and 5.6. The interleave heights are $100 \mathrm{~nm}, 200 \mathrm{~nm}$ and $300 \mathrm{~nm}$ respectively. The pullaway height was $400 \mathrm{~nm}$ in all the three cases. Other parameters including scan speed $(130 \mu \mathrm{m} / \mathrm{s})$ were also held constant throughout the experiment. As seen on line profile shown in Figure 5.4, the images are of a half wave with the wave crest (white or highest voltage) on the left and the wave trough (black or lowest voltage) on the right. At this resolution, light and dark patches corresponding to the north and south poles of individual magnetic particles may be observed.

In Figure 5.4 (100 nm interleave height) three areas are marked; two areas contain surface features which have influenced the MFM image and one area contains a purely magnetic feature. The same areas are marked in Figures 5.5 and 5.6. In Figure 5.5 (200 
$\mathrm{nm}$ interleave height) one of the surface features is no longer present and the other surface feature's influence is greatly reduced. The magnetic feature in Figure 5.5 is still present but in less detail as compared to Figure 5.4. In Figure 5.6 (300 nm interleave height) neither of the surface feature are influencing the image, but the magnetic feature is extremely blurred representing a significant loss of information at the domain level.

From these observations an interleave height of $200 \mathrm{~nm}$ was chosen for the other studies as a compromise between the level of magnetic detail present in a given image and eliminating surface influences. This also highlights the need for surfaces to be flat and free from debris so that a minimum interleave height can be maintained in order to obtain the highest magnetic resolution possible. 


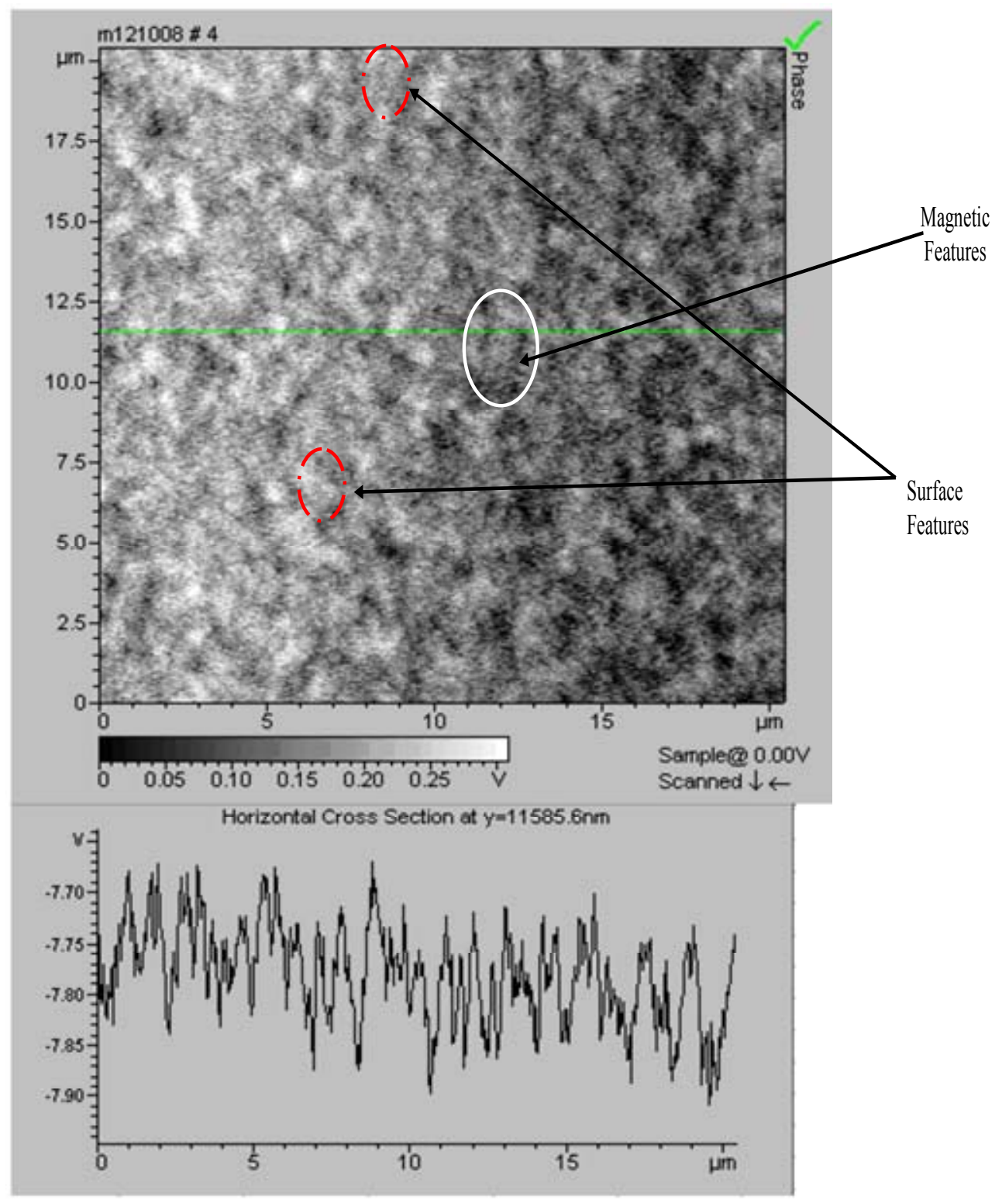

Figure 5.4 MFM image of $2 \mathrm{kHz}$ sine wave with interleave of $100 \mathrm{~nm}$. The red dashed circles represent area with surface influences and the solid white circle contains a magnetic feature 


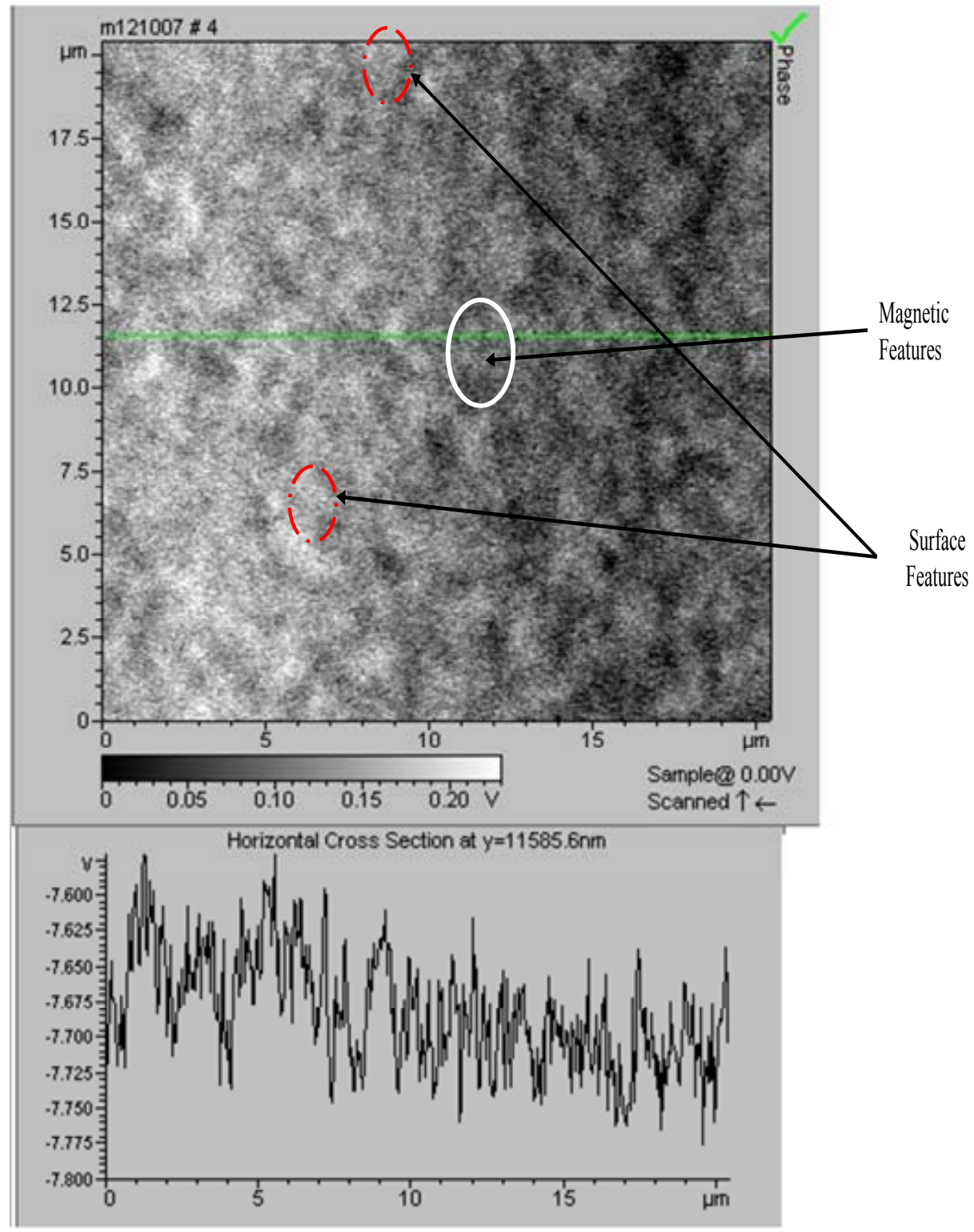

Figure 5.5 MFM image of the same area of audiotape as Figure 5.4 ( $2 \mathrm{kHz}$ sine wave) with an interleave height of $200 \mathrm{~nm}$. The circled areas are in same locations as in Figure 5.4 


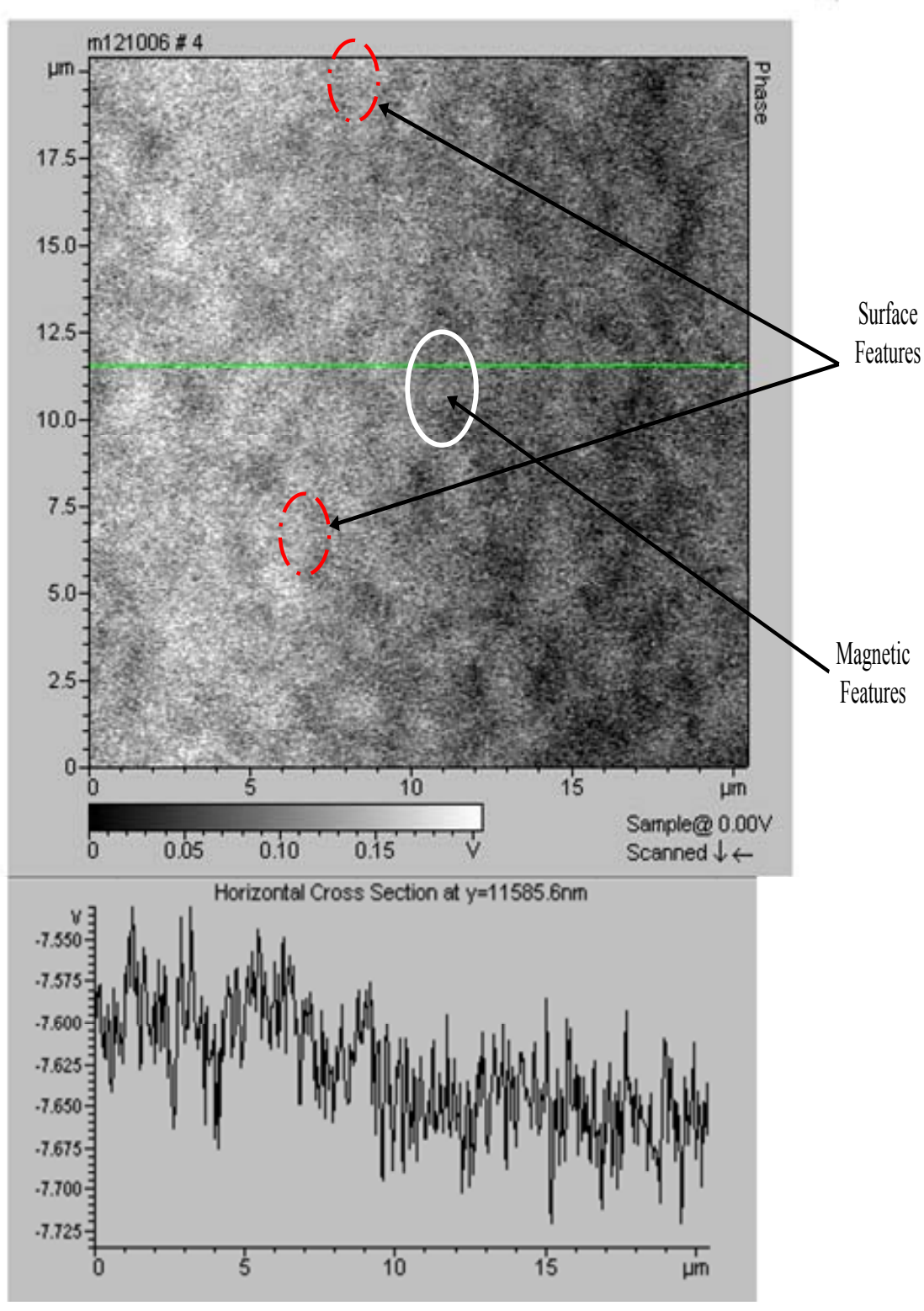

Figure 5.6 MFM image of the same area of audiotape as Figures 5.4 and 5.5 ( $2 \mathrm{kHz}$ sine wave) with an interleave height of $300 \mathrm{~nm}$. The circled areas are in same locations as in Figures 5.4 and 5.5 


\subsection{Tip Speed Study}

As the time required to recover data using MFM is long, a study was conducted to increase the tip or scan speed without degrading the signal. An initial study revealed that a tip speed of $130 \mu \mathrm{m} / \mathrm{s}$ produced high quality images with excellent reproducibility, so this value was chosen to be the standard speed to which other tip speeds were compared. Other tip speeds studied here were $157 \mu \mathrm{m} / \mathrm{s}, 200 \mu \mathrm{m} / \mathrm{s}, 244 \mu \mathrm{m} / \mathrm{s}$ and $270 \mu \mathrm{m} / \mathrm{s}$. The maximum tip speed for our instrument was $270 \mu \mathrm{m} / \mathrm{s}$. Interleave height and pullaway values were fixed at $200 \mathrm{~nm}$ and $400 \mathrm{~nm}$ respectively.

The signals used for these studies were a strong $5 \mathrm{kHz}$ sine wave and a weak 14 $\mathrm{kHz}$ sine wave written simultaneously to both tracks. Then one of the tracks was erased with the input of a null signal. This produced 3 regions of interest with different signal strengths: strong, weak and erased. The different regions of interest are shown in Figure 5. 7.

The MFM images of each region for each tip speed was pixel-by-pixel converted to a grayscale image and compared pixel-by-pixel to the grayscale image taken at 130 $\mu \mathrm{m} / \mathrm{s}$ using the correlation techniques developed by Terry R. Ferrett [4]. In these calculations, a correlation factor of 1.00 indicates $100 \%$ agreement between the image in question and the image taken at $130 \mu \mathrm{m} / \mathrm{s}$. The procedure for processing and converting MFM images to grayscale are given in Appendix A and Appendix C respectively.

A plot showing correlation values vs. tip speed for different regions is shown in Figure 5.8. The following observations were made.

i) The correlation values of strong and weak signal regions were higher and comparable and virtually independent of tip speed up to $270 \mu \mathrm{m} / \mathrm{s}$. 
ii) For the erased data, there is some variability for the strong and weak signals.

For the strong signal, the correlation is quite high at $130 \mu \mathrm{m} / \mathrm{s}$ and then drops to about 0.5 for tip speed of $200 \mu \mathrm{m} / \mathrm{s}$ and higher. For the weak signal, the correlation is in the range of 0.6-0.7 and relatively independent of tip speed. This shows that the tip speed have to be $200 \mu \mathrm{m} / \mathrm{s}$ or less for the erased signals.

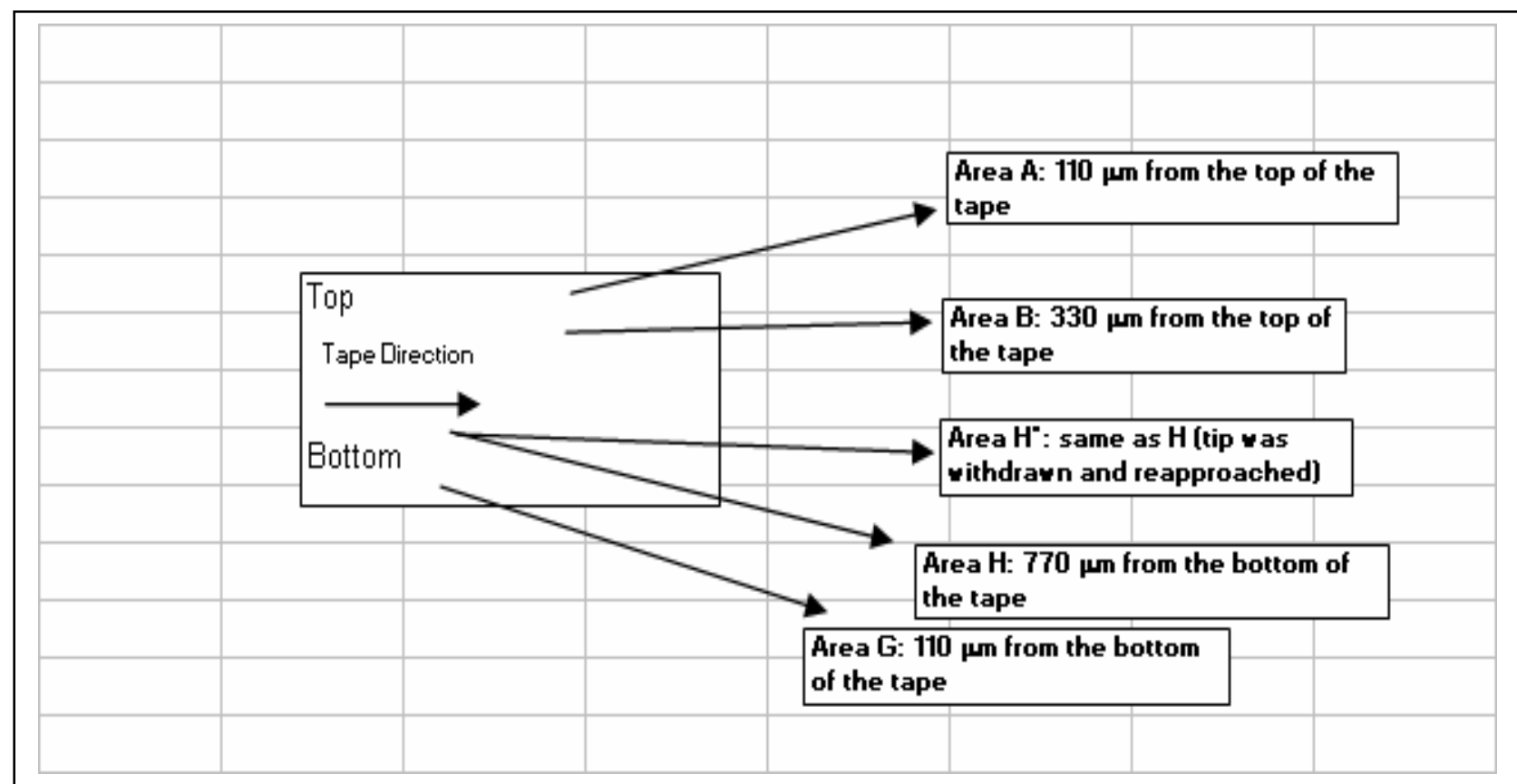

Figure 5.7 Schematic of different areas of interest 


\section{Effect of Tip Speed}

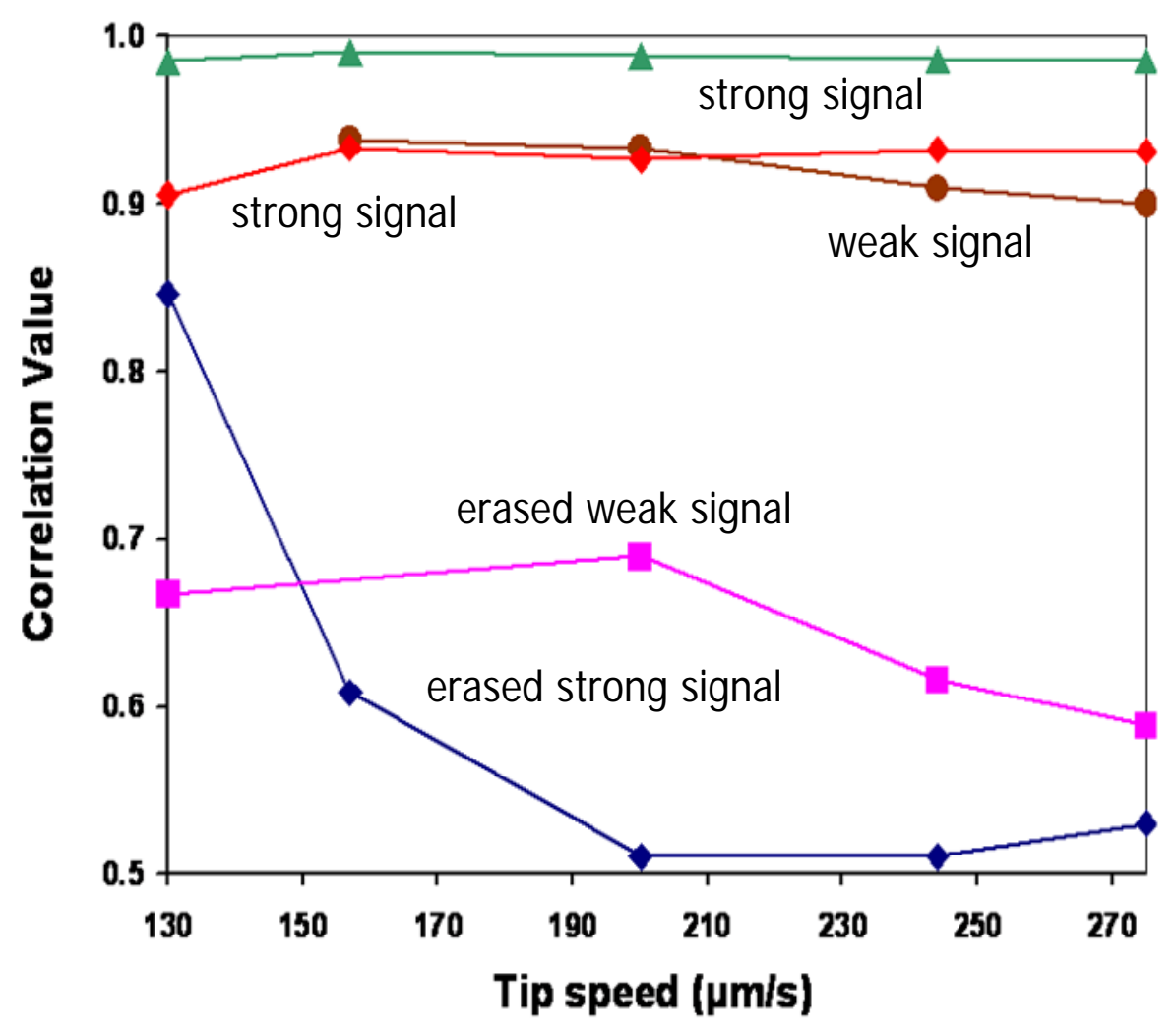

Figure 5.8 Plot of Correlation Value vs. Tip speed

The scanning time with a tip speed of $130 \mu \mathrm{m} / \mathrm{s}$ for an area of $90 \times 90 \mu \mathrm{m}^{2}$ of an audiotape was 38 minutes. Assuming a linear decrease, by adopting a scan speed of 270 $\mu \mathrm{m} / \mathrm{s}$ for the areas with strong and weak signals, the scanning time could be virtually halved. 


\subsection{Frequency Study}

This study was performed to observe how the frequencies of the recorded wave impacted on the MFM image. The frequencies recorded on the tape for this research were $10 \mathrm{kHz}, 15 \mathrm{kHz}, 20 \mathrm{kHz}, 22.5 \mathrm{kHz}, 23 \mathrm{kHz}$ and $24 \mathrm{kHz}$. All the waveforms were of sinusoidal nature. The MFM images of all these frequencies are given in the Figures 5.9, $5.8,5.9,5.10,5.11$ and $5.12,5.13,5.14$

The following observations were noteworthy.

i) No MFM signal was visible to the naked eye in the data collected for the $24 \mathrm{kHz}$ sample.

ii) As the frequency of the signal increased, there was a decrease in the intensity of the playback signal.

iii) There was a steady decrease in the playback signal even when input signal was maximized.

The audible frequency range is from $20 \mathrm{~Hz}$ to $20 \mathrm{kHz}$. From the data shown, it can be inferred that signals above the audible range can be recorded in the audiotape and retrieved using MFM. Even though the correlation model developed by my colleague, Mr. Terry R. Ferrett was not used to retrieve signal from the $24 \mathrm{kHz}$ MFM image, it can still be said with certainty that signals above the audible range can be recorded and retrieved using MFM. Thus this technique of MFM can be used to detect signals that are recorded for covert purposes. 


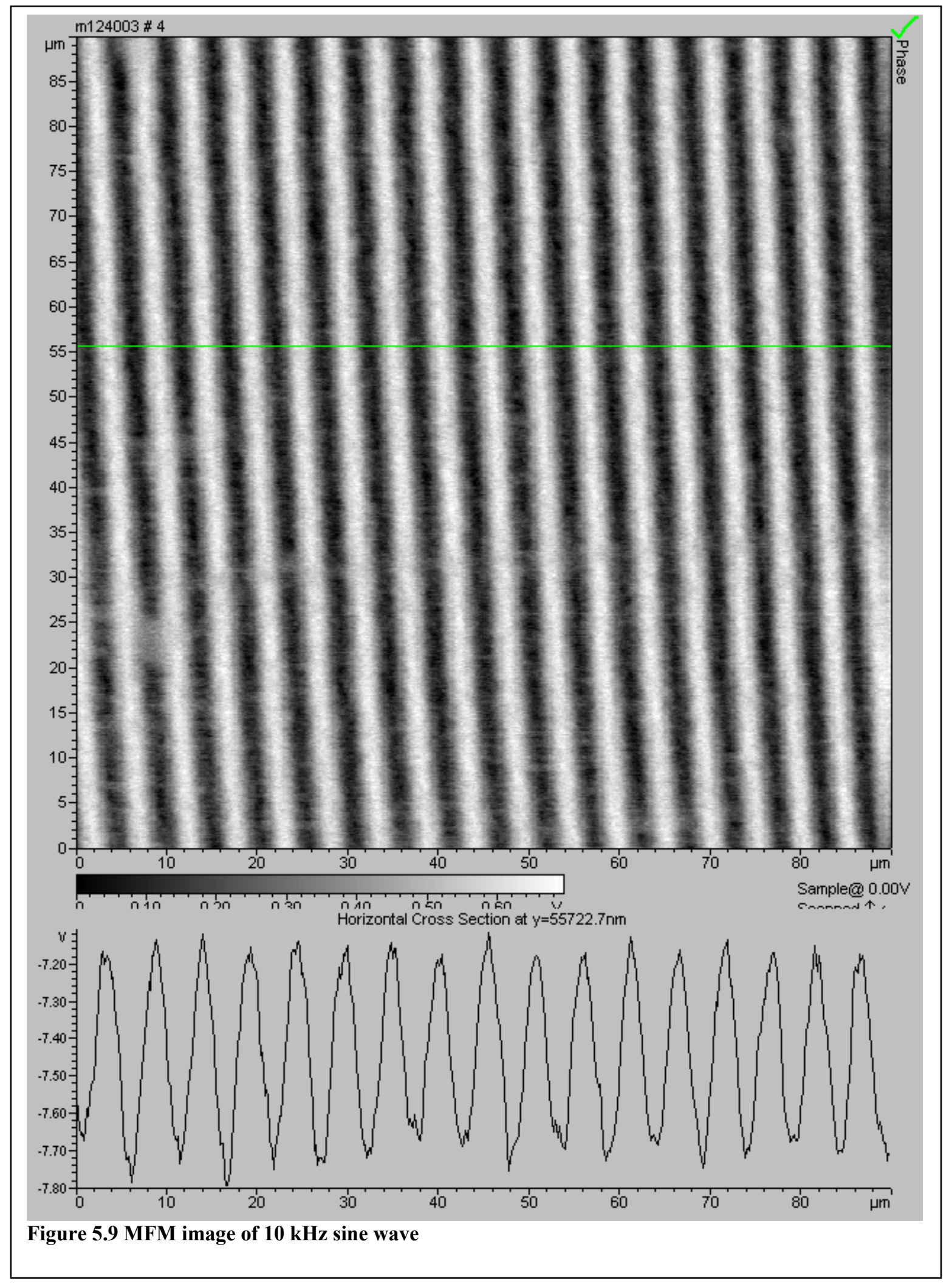




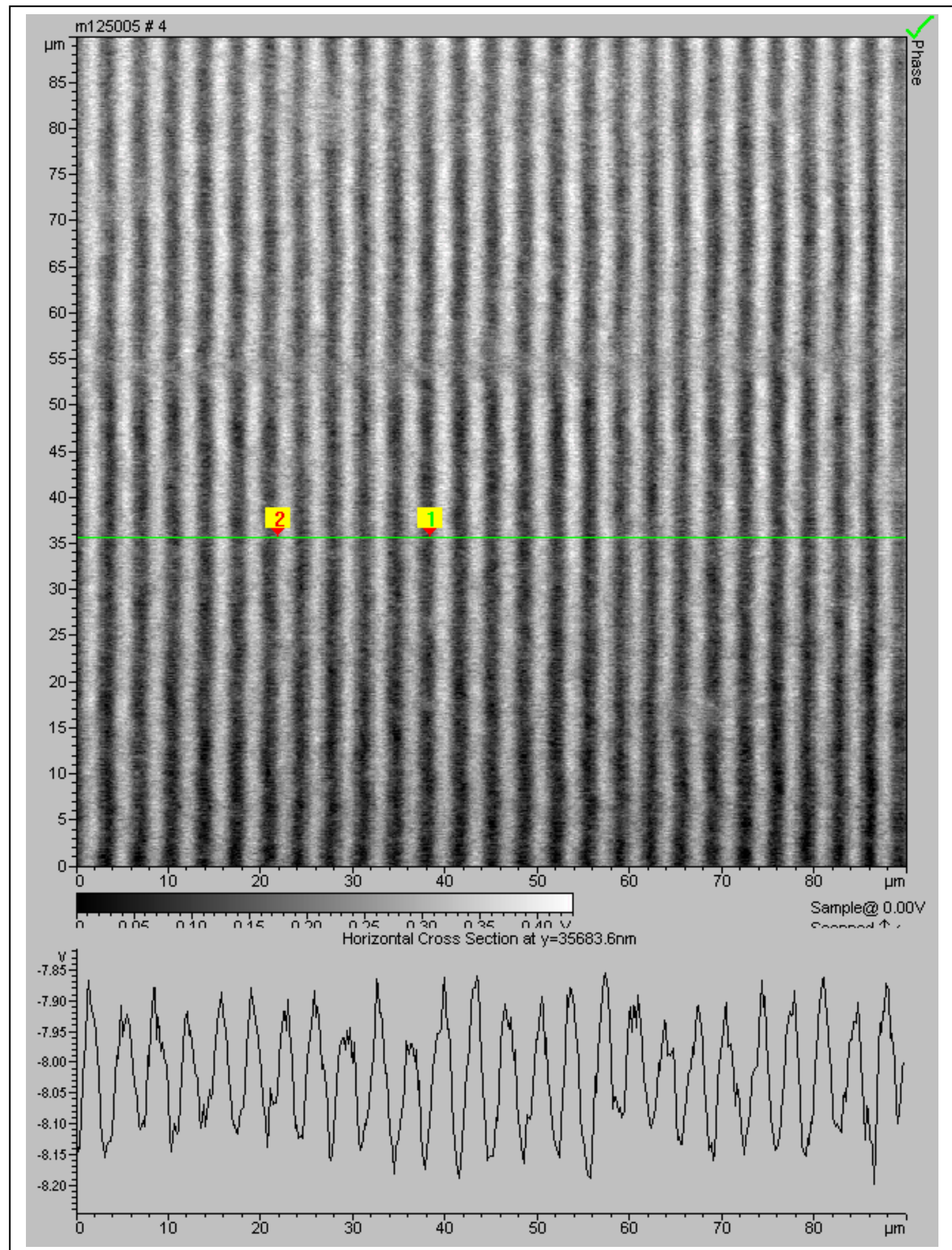

Figure 5.10 MFM image of $15 \mathrm{kHz}$ sine wave 


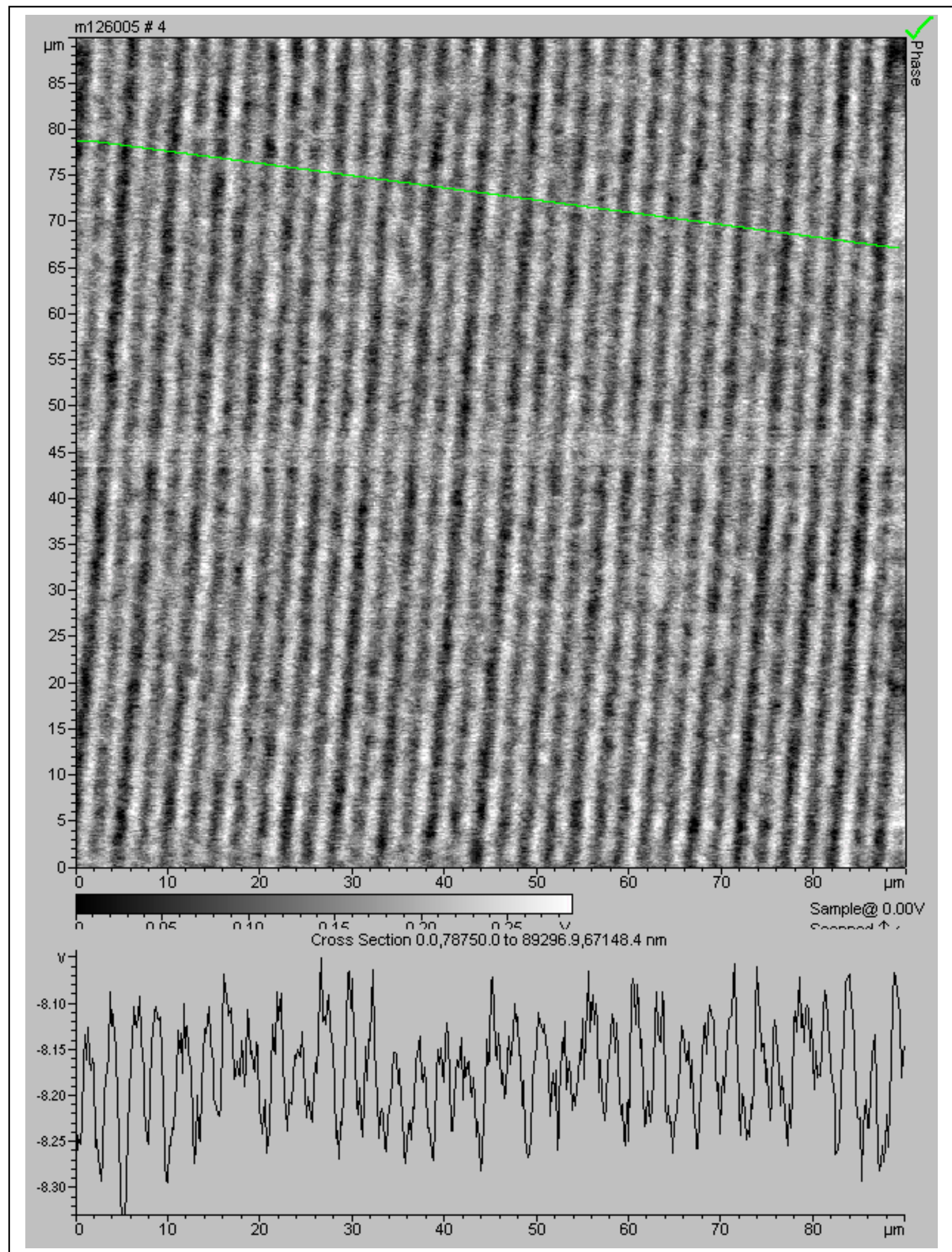

Figure 5.11 MFM image of $20 \mathrm{kHz}$ sine wave 


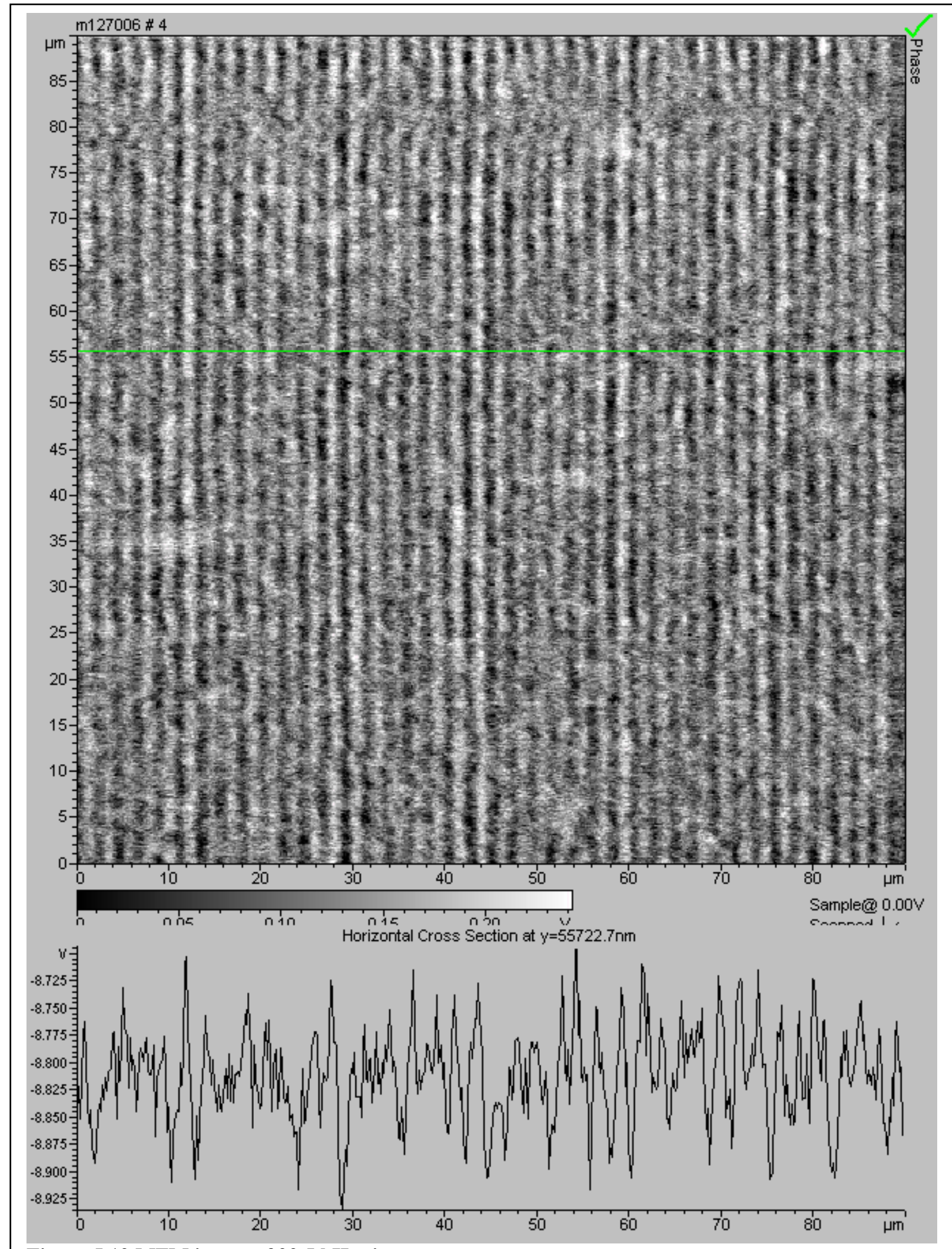

Figure 5.12 MFM image of $22.5 \mathrm{kHz}$ sine wave 


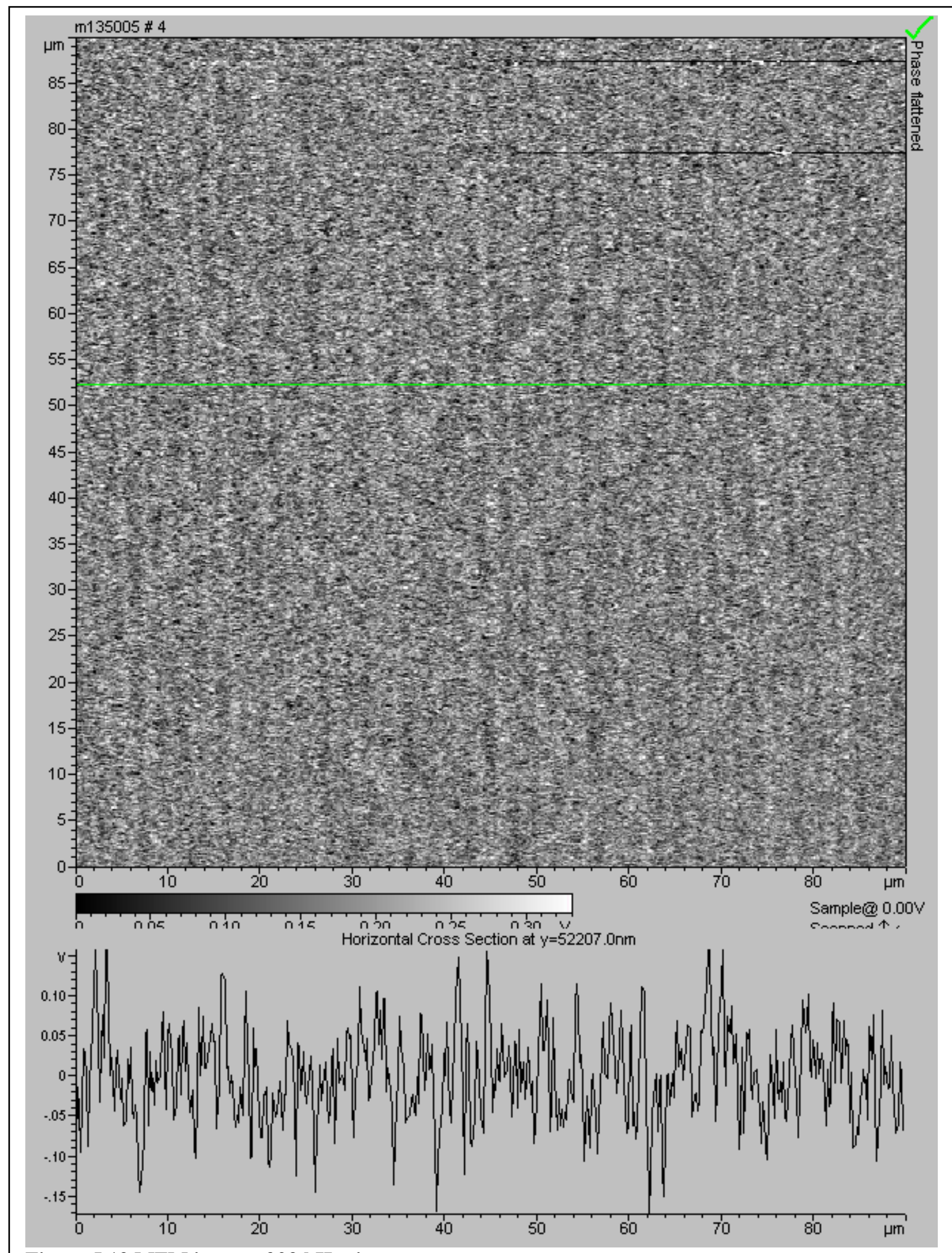

Figure 5.13 MFM image of $23 \mathrm{kHz}$ sine wave 


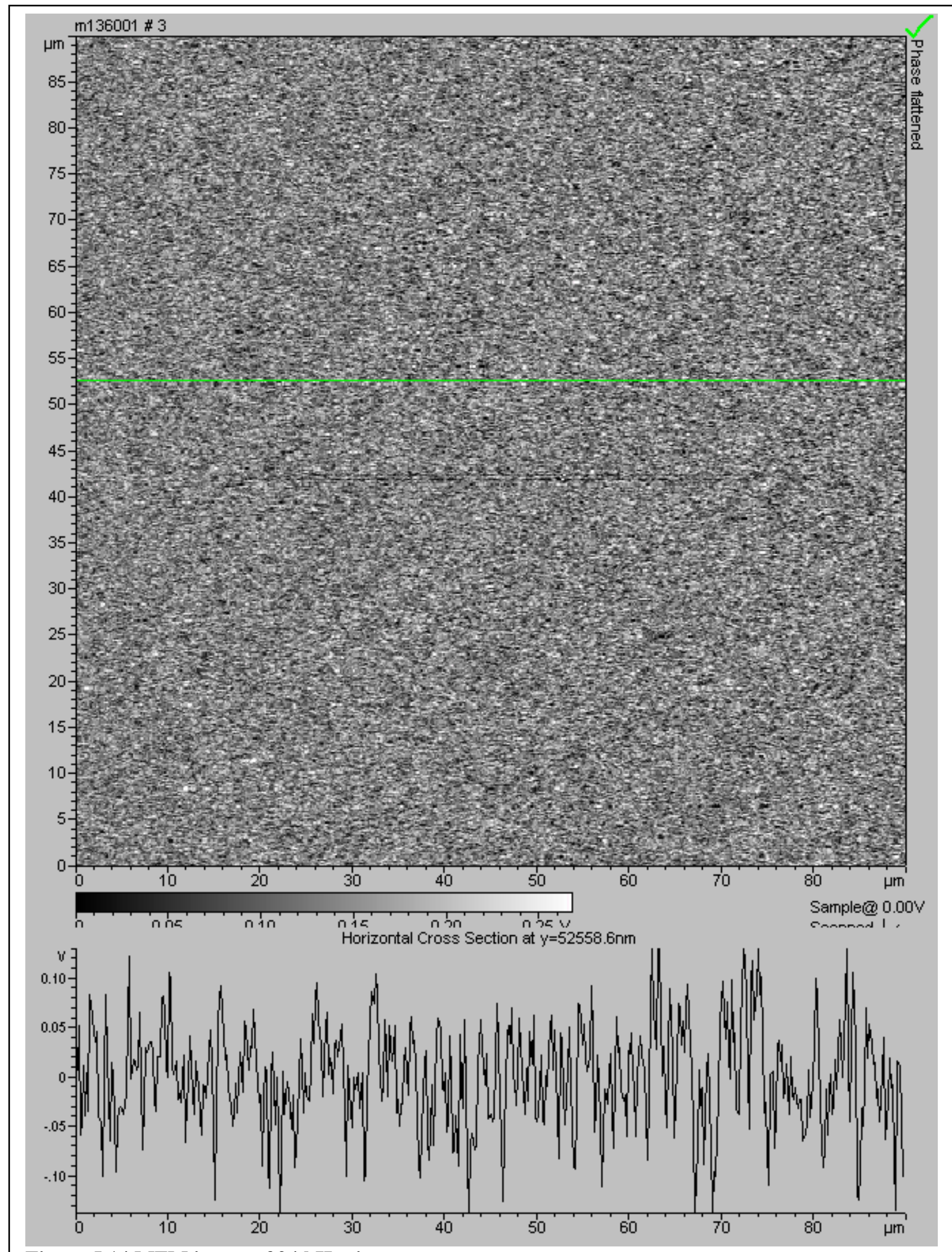

Figure 5.14 MFM image of $24 \mathrm{kHz}$ sine wave 


\subsection{Calculation of Time for Recovery of data}

In all the studies explained earlier, optimum scan conditions were typically 130 $\mu \mathrm{m} / \mathrm{s}$ at an interleave height of $200 \mathrm{~nm}$. Under these conditions a scan time of 38 minutes was required for a $90 \mu \mathrm{m} \times 90 \mu \mathrm{m}$ scan. Using this as the basis, 2.9 days are required to scan $1 \mathrm{~cm}$ of audiotape.

Another way of assessing the data recovery time is to consider the time to analyze one minute of playback. Given that the spool speed is $4.7 \mathrm{~cm} / \mathrm{s}$, one minute of playback is $285.0 \mathrm{~cm}$. Thus, the time to analyze this length of tape would be 2.3 years.

The primary application of MFM would be for the retrieval of erased or overwritten data. Moreover, it is shown in Section 5.3 that tip speed cannot always be increased without a significant loss of data (using correlation) for erased data. Therefore, even if speeds could be increased by a factor of 3 times, this only lowers the data retrieval time to approximately 1 day for $1 \mathrm{~cm}$ of tape and approximately 1 year for one minute of playback.

Clearly increasing tip speed by a factor of 3 or even 10 is useful but not sufficient for making MFM a practical method of data retrieval for audiotape. One way to overcome this problem is through the use of multiple tip arrays. A similar and interesting piece of research has been performed by Cherunini et.al [18] by what is better known as the concept of "millipede". In "millipede", an array containing 32 x 32 tips was used to read, write and erase data. Also in this highly parallel data storage technique, high densities up to of 0.5 to $1 \mathrm{Tbit} / \mathrm{in}^{2}$ were achieved. The schematic of this set up is shown in the Figure 5.15.

For the moment, if we assume the possibility of similar technique in this research, 
fabrication technology will allow arrays of 32 x 32 tips [18]. Assuming suitable readout capabilities, this will reduce the retrieval time for $1 \mathrm{~cm}$ of audiotape to approximately 2.3 hours and to 27.9 days for 1 minute of playback. However there is still tremendous amount of research and development to utilize simultaneous scanning of MFM tip arrays. Challenges lie in the areas of fabrication, readout and processing the simultaneous data from such device arrays.

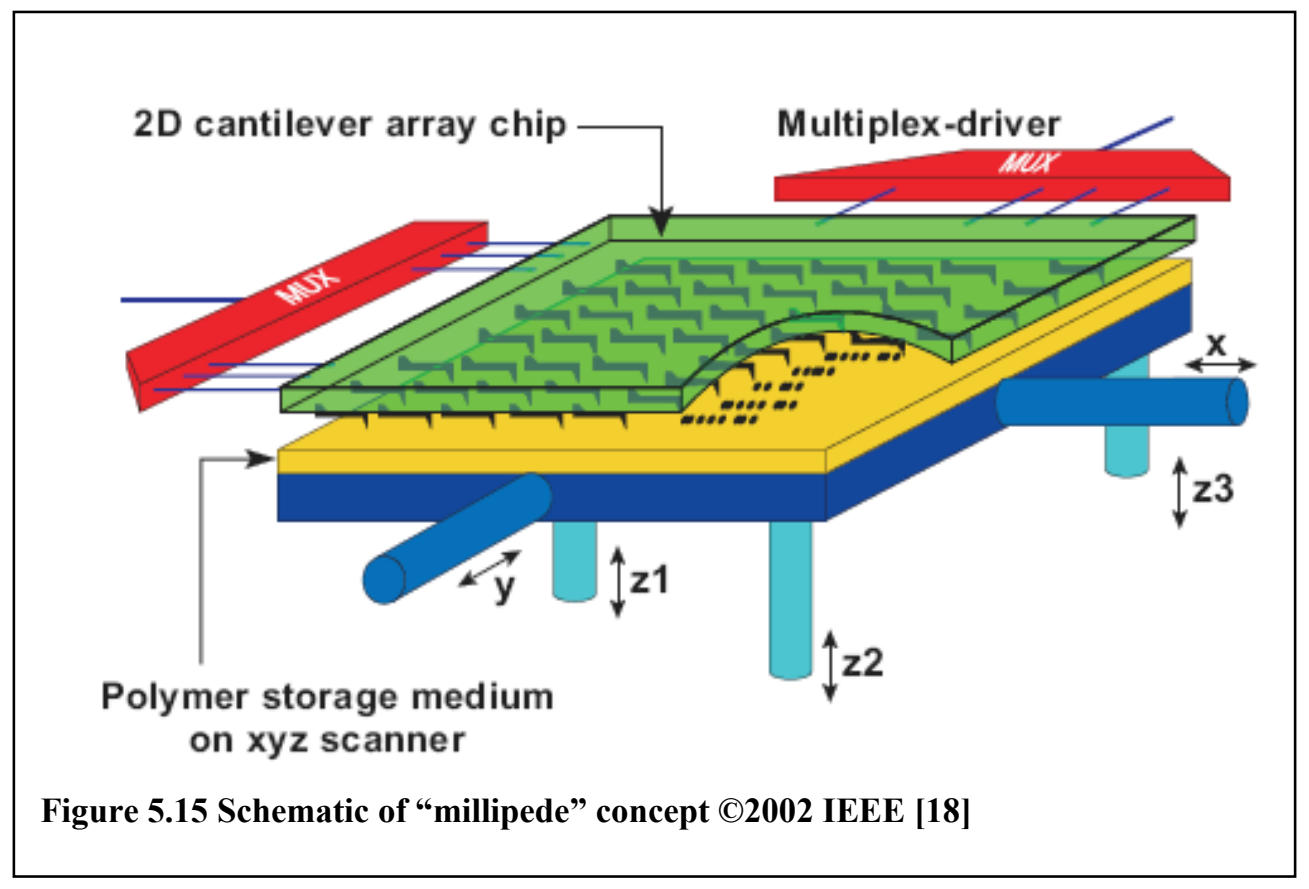




\section{Chapter 6 Conclusions}

The results of prior studies in the lab have shown that significant amounts of signal can be extracted from erased audiotape media using MFM [4]. The aim of this thesis has been to optimize MFM parameters for retrieval of erased or altered signals from audiotape. Based on the discussion that signal distortion due to the recording process was minimum with the sine waves, all waveforms that were used for this research were sinusoidal. The two key parameters found to effect MFM data retrieval were interleave height (i.e. the tip to sample distance) and tip speed.

Studies of MFM signal intensity and signal to noise ratio verses interleave height were performed. Because the RMS roughness of the audiotape is in the range of 25-45 $\mathrm{nm}$, with occasional features in excess of $100 \mathrm{~nm}$, interleave heights of $100 \mathrm{~nm}-300 \mathrm{~nm}$ were investigated. The data revealed that an interleave height of $100 \mathrm{~nm}$ provided the most magnetic detail, but also had a significant amount of interference from nonmagnetic surface features. In contrast, an interleave height of $300 \mathrm{~nm}$ had almost no interference from surface features, but lacked details produced by individual particles in the media. An interleave height of $200 \mathrm{~nm}$ was settled because interference from nonmagnetic surface features was minimal while retaining most of the magnetic detail found in images produced using a $100 \mathrm{~nm}$ interleave height.

The tip speed study was undertaken to determine the extent to which data acquisition could be reduced using our instrumentation. The results of the studies showed that correlation values as high as $60 \%$ could be obtained for erased signals using a tip speed of $270 \mu \mathrm{m} / \mathrm{s}$. This was the maximum tip speed allowed by our instrument. This represents a doubling of the tip speeds over the minimum value $(130 \mu \mathrm{m} / \mathrm{s})$ used in the 
experiments with relatively little falloff in correlation values in some cases.

A series of experiments was performed to determine the effect of signal frequency on the recording process. From the data available, it was concluded that the recording efficiency dropped with the increase of frequency. However, more importantly, it was observed that frequencies above the audio range could be used for convert purposes if desired.

The results of this optimization study show that using current instrumentation data acquisition time for erased signals can be reduced by at most a factor of two. This is far short of the reductions needed for the construction of a practical instrument. To achieve this goal, advances in MFM and scanning probe microscopy are needed. One such advance is the development of multi-tip arrays for MFM. Given current micro-fabrication methods, this is now possible. However, additional work must be done in the areas of magnetic tip response and data processing for such arrays. 


\section{Appendix A}

\section{Procedure for Operating MFM [19]}

\section{Alignment of Laser}

1. Open the PicoScan data acquisition software program.

2. Place the scanner on the mounting jig as shown in the Figure A.1

3. Use tweezers to place the cantilever while lifting the spring using the metal piece provided.

4. Insert the scanner back into the microscope and tighten the screws to arrest the motion of the scanner.

The most important part of the procedure is the alignment of the laser beam.

i) Place a small white sheet of paper under the microscope

ii) Once the laser beam switch is turned on, adjust the laser adjustment screws to have a clear spot of laser on the white paper or the screen of the scanner.

iii) Use the left screw to push the laser spot forward until it disappears. When the spot disappears it means that it has reached the tip of the cantilever. Now bring it back so that the spot is visible once again.

iv) Use the right screw to move the spot along the horizontal direction. When it disappears, bring it back a bit.

v) Now use the same screw to move the spot in the opposite direction so that the diffracted laser beam is visible on both the screen and the paper. At this position the laser has reached the end of the cantilever.

vi) Continue to move the laser spot until it reappears. Now it is in between the two legs of the cantilever. Continuing the motion in the same direction will 
make the laser spot disappear once again, indicating that it has reached the other end of the cantilever leg.

vi) Once the two ends of the cantilever is known, find the centre of the cantilever. Using the left screw, move the laser towards the cantilever's tip. Once the tip has been reached, the spot on the paper will be very unclear, almost invisible.

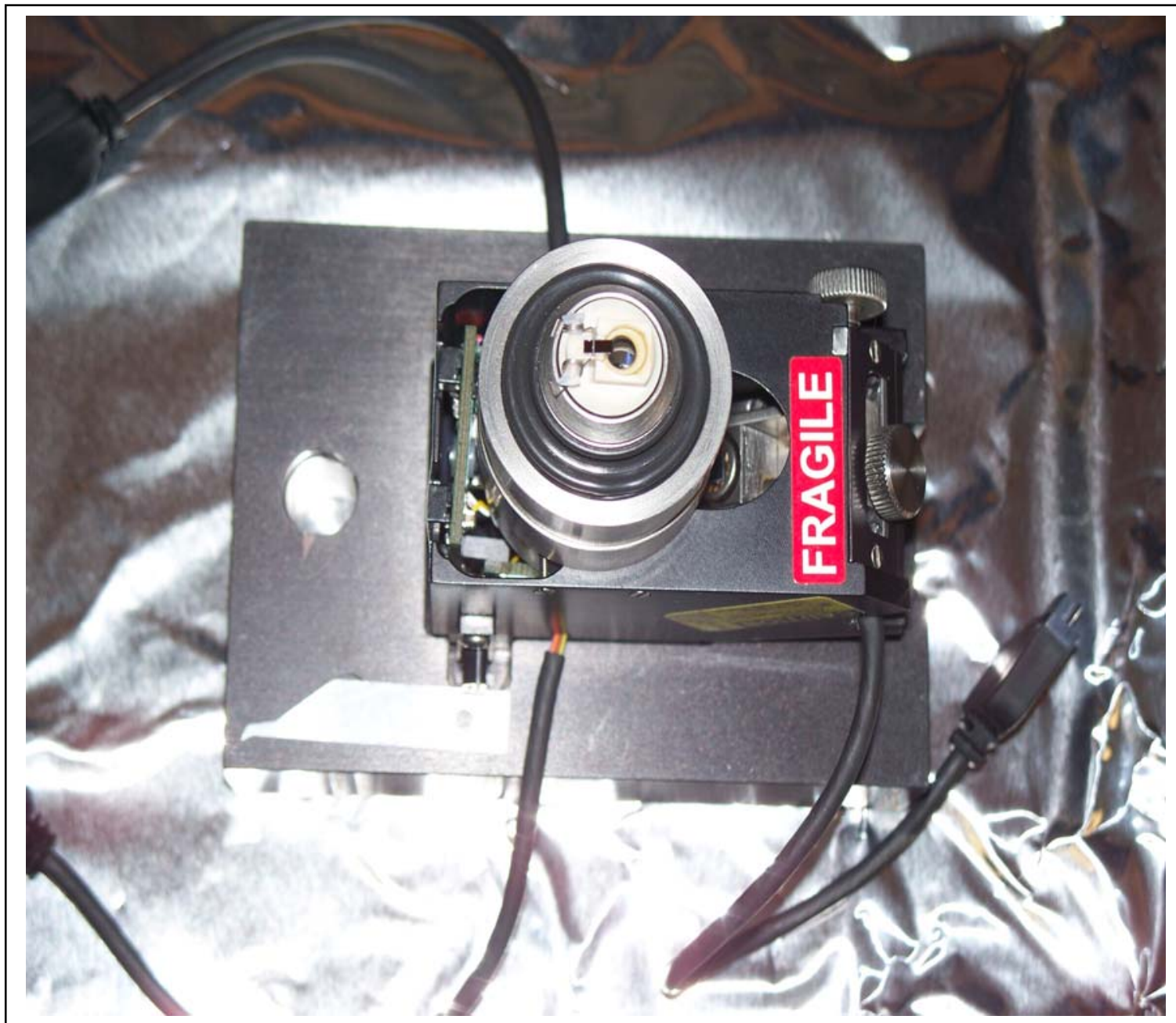

Figure A.1 Photograph of scanner on the mounting jig 


\section{Placing the Sample}

1 Place the sample (audiotape) on the disc using tweezers and stick the ends of the sample using cellophane.

2 Make a diagram of this setup and mark the areas under investigation. An example of such a schematic is given in Figure A.2.

3 Place the sample plate in position underneath the microscope. The sample plate will exactly fit once the holes on it pass through the clips. The magnet will hold the plate and prevent them from falling down.

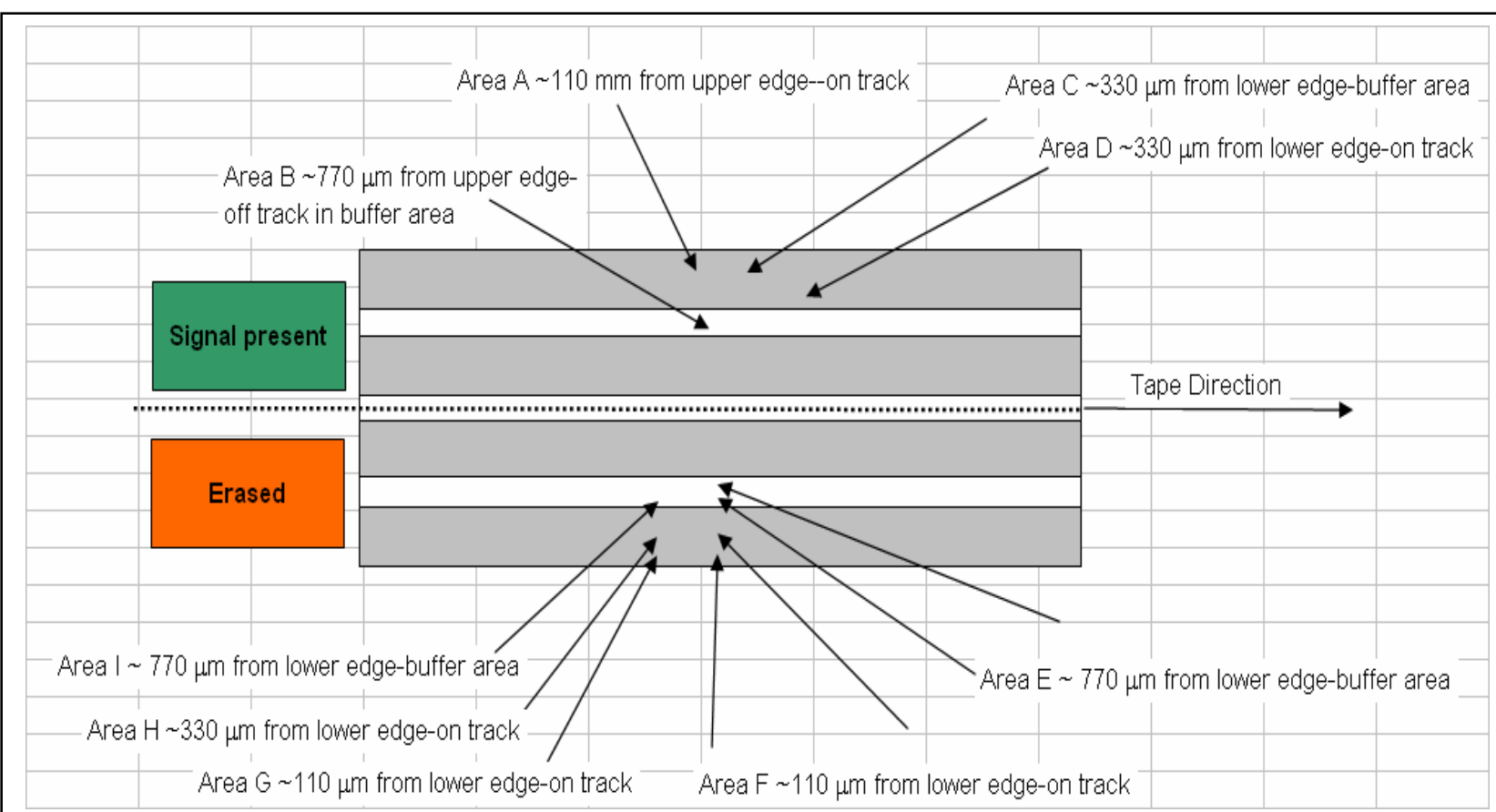

Figure A.2 Schematic of different areas of scans 
4 Use the X, Y set of screws to position the sample so that the area under investigation is right below the tip.

5 Now setup the software to work in MFM mode. Also make sure to include the functions -interleave and pull away parameters. Approach the tip.

6 Start the scan and adjust the parameters until system gets stabilized.

7 When the scan is over, store the file in the same directory as other images for consistency.

Note: The first scan is usually done with the Standard Sample whose profile is already known. This way it helps the user to verify the parameters listed in the profile of the Standard Sample. Once that is set, the user has to just change the sample without the need for changing the other parameters. 


\section{Appendix B}

\section{Procedure for Processing MFM Images}

1 Open the Scanning Probe Image Processor (SPIP) software.

2 Select the MFM image to be processed using the 'File open' option in the drop down menu.

3 At the top of the menu bar, select the Plane Correction Dialog option. Choose one of the options under Global Correction menu and set it to the desired degree ( 0 to 5). Similarly select one of the alternatives under Line-Wise correction option. Click 'Apply' button to have the image processed. Save the image in the desired location with a suitable file name. For the second image of the MFM to be processed, transfer the second image to the main image by right clicking on the second image and choosing the 'Exchange with Main Image' option. Once that is done follow the same procedure as described above.

Now choose the menu 'Processing' and select the option 'fourier dialog' under the pick 'fourier'. In the 'fourier dialog' select the 'Filter' button. Choose the option 'Ideal' under 'Band Filtering'. Set the type of filter to 'Low Pass' and give the desired value under the option 'Wave Length' (it was $500 \mathrm{~nm}$ for this research). Once that is set, click on the 'Inverse FFT'. This will create a couple of images with Inverse FFT and Inverse difference. Right click on these images and choose 'save as' to save them in the desired location. 


\section{Appendix C}

\section{Procedure for Converting MFM Images to Grayscale}

1. Open 'CorelDRAW Graphics Suite X3' program and choose 'Corel PHOTOPAINT X3'.

2. Open the file to be processed by selecting the option 'File' on the menu.

3. Once the file is opened, select 'Image' and choose 'Convert to Grayscale (8-bit)' option.

4. Save the resulting image in the desired directory. 


\section{Bibliography}

[1] designboom, "Cassette tape culture,"

http://www.designboom.com/contemporary/cassettes.html, [Online; accessed 9-

September-2008].

[2] Pappas, David P.; Arnold, C. Stephen; Shalev, Gideon; Eunice,

Carla; Stevenson, D.; Voran, Stephen D.; Read, Michael E.; Gormley, E.

M.; Cash, Jim; Marr, Ken; Ryan, James J, “Second-harmonic magneto resistive imaging to authenticate and recover data from magnetic storage media," Proc. SPIE Vol. 4232, Page(s) 11-18, Feb 2001. (Permission has been granted by Pappas on 12/04/2008)

[3] R. D. Gomez, A. A. Adly , I. D. Mayergoyz , E. R. Burke, "Magnetic force scanning tunneling microscope Imaging of overwritten data," IEEE Transactions on Magnetics, Volume 28, no 5, Pages(s): 3141-3143, September 1992. (Permission has been granted by Tony Vengraitis, IRS Specialist, IEEE on 12/01/2008)

[4] Terry R. Ferrett, Data Recovery from Magnetic Media Using Magnetic Force Microscopy, Master of Science thesis, West Virginia University, 2008. [5] C.Denis Mee, Eric D. Daniel, "Magnetic Recording Technology," Second Edition, McGraw Hill Publishers, Page 3.67

[6] Umeki, S.; Saitoh, S.; Imaoka, Y, “A new high coercive magnetic particle for recording tape," IEEE Transactions on Magnetics, Volume 10, Issue 3, Page(s): 655 656, September 1974.

[7] D. Rugar, H.J. Mamin, P. Guethner, S.E. Lambert, J.E. Stem, I.

McFadyen and T. Yogi, "Magnetic force microscopy: general principles and application to longitudinal recording media”, J.Ap Phys., Vo1.68, Page 1169, 1990.

[8] A.Wadas, P. Griitter and H.-J. Giintherodt," Analysis of in-plane bit structure by magnetic force microscopy", J. Appl. Phys., Volume 67, Page(s) 3462, 1990 and references therein.

[9] R.D. Gomez, A.A. Adly, I.D. Mayergoyz and E.R. Burke, "Magnetic field imaging by using magnetic force scanning tunneling microscopy”, Appl Phys. Lett Vol.60, Page.906, 1992.

[10] "MikroMash-Library-Biology-Viruses" 
http://www.spmtips.com/library/biology/viruses / [Online, accessed 22nd September 2008]

[11] R.d.S. Pereira, "Atomic force microscopy as a novel pharmacological tool", Biochemical Pharmacology, Volume 62, no 8, Page(s) 975-983, 2001.

[12] Gernot Friedbacher and Harald Fuchs, "Classification of Scanning Probe Microscopies" Pure Appl. Chem, Volume 71, no 7, Page(s) 1337-1357, 1999.

[13] A.A. Woodworth, "Palladium and nickel interactions with stepped 6H-Silicon carbide", Ph.D. thesis, West Virginia University, 2005.

[14] J. W. Cross, "Scanning Probe Microscopy (SPM),"

http://www.mobot.org/jwcross/spm/, [Online; accessed $22^{\text {nd }}$ September 2008].

[15] Rebecca Howland and Lisa Benatar; "A Practical guide to Scanning Probe Microscopy", First Edition.

[16] S. L. Tomlinson and A. L. Farley, "Micromagnetic model for magnetic force microscopy tips", J. Appl. Phys., Volume. 81, no. 8, Page(s). 5029-5031, April 1997. [17] "Type: MFMR"

http://www.nanoworld.com/print/J-01.html [Online, accessed December $2^{\text {nd }}$ 2008] [18] G.Cherubini, T.Antonakopoulos, P.Bachtold, G.K.Binnig, M.Despont, U.Drechsler, A.Dholakia, U.Durig, E.Eleftheriou, B.Gotsmann, W.Haberle, M.A.Lantz, T.Loeliger, H.Pozidis, H.E.Rothuizen, R.Stutz and P.Vettiger, IEEE, Page(s) 121-125, Sept 2002. (Permission has been granted by Tony Vengraitis, IRS Specialist, IEEE on 12/01/2008) [19] Digital Instruments, Magnetic Force Microscopy (MFM) Manual, Support Note No 229, Rev.B. 